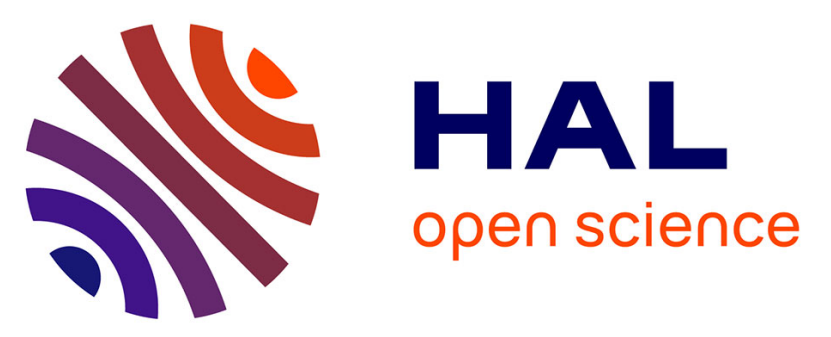

\title{
Negative Pressure Engineering with Large Cage Cations in 2D Halide Perovskites Causes Lattice Softening
}

Xiaotong Li, Yongping Fu, Laurent Pedesseau, Peijun Guo, Shelby Cuthriell, Ido Hadar, Jacky Even, Claudine Katan, Constantinos C Stoumpos, Richard Schaller, et al.

\section{To cite this version:}

Xiaotong Li, Yongping Fu, Laurent Pedesseau, Peijun Guo, Shelby Cuthriell, et al.. Negative Pressure Engineering with Large Cage Cations in 2D Halide Perovskites Causes Lattice Softening. Journal of the American Chemical Society, 2020, 142 (26), pp.11486-11496. 10.1021/jacs.0c03860 . hal-02764729

\section{HAL Id: hal-02764729 \\ https://hal.science/hal-02764729}

Submitted on 16 Jun 2020

HAL is a multi-disciplinary open access archive for the deposit and dissemination of scientific research documents, whether they are published or not. The documents may come from teaching and research institutions in France or abroad, or from public or private research centers.
L'archive ouverte pluridisciplinaire HAL, est destinée au dépôt et à la diffusion de documents scientifiques de niveau recherche, publiés ou non, émanant des établissements d'enseignement et de recherche français ou étrangers, des laboratoires publics ou privés. 


\title{
Negative Pressure Engineering with Large Cage Cations in 2D Halide Perovskites Causes
}

\section{Lattice Softening}

Xiaotong Li ${ }^{\dagger}$ Yongping Fu,$^{\dagger}$ Laurent Pedesseau $"$, Peijun Guo ${ }^{\ddagger}$ Shelby Cuthriell ${ }^{\dagger}$ Ido Hadar, ${ }^{\dagger}$ Jacky Even, "Claudine Katan, ${ }^{\S}$ Constantinos C. Stoumpos, ${ }^{\nabla}$ Richard D. Schaller,,+ Elad Harel $^{\diamond}$ and Mercouri G. Kanatzidis",†

†Department of Chemistry, Northwestern University, 2145 Sheridan Road, Evanston, Illinois 60208, United States

†enter for Nanoscale Materials, Argonne National Laboratory, 9700 South Cass Avenue, Lemont, Illinois 60439, United States

"Univ Rennes, INSA Rennes, CNRS, Institut FOTON, UMR 6082, Rennes F-35000, France

§Univ Rennes, ENSCR, INSA Rennes, CNRS, ISCR (Institut des Sciences Chimiques de Rennes), UMR 6226, Rennes F-35000, France

$\nabla$ Department of Materials Science and Technology, Voutes Campus, University of Crete, Heraklion GR-70013, Greece

${ }^{\bullet}$ Department of Chemistry, Michigan State University, East Lansing, Michigan 48824, United States

\begin{abstract}
Organic-inorganic hybrid halide perovskites are promising semiconductors with tailorable optical and electronic properties. The choice of A-site cation to support a three-dimensional (3D) perovskite structure $\mathrm{AMX}_{3}$ (where $\mathrm{M}$ is a metal, and $\mathrm{X}$ is a halide) is limited by the geometric Goldschmidt tolerance factor. However, this geometric constraint can be relaxed in twodimensional (2D) perovskites, providing us an opportunity to understand how various the A-site cations modulate the structural properties and thereby the optoelectronic properties. Here, we report the synthesis and structures of single-crystals $(\mathrm{BA})_{2}(\mathrm{~A}) \mathrm{Pb}_{2} \mathrm{I}_{7}$ where $\mathrm{BA}=$ butylammonium, and $\mathrm{A}=$ methylammonium (MA), formamidinium (FA), dimethylammonium (DMA) or guanidinium (GA), a series of A-site cation varied in size. Single-crystal X-ray diffraction reveals that the MA, FA, and GA structures crystallize in the same $C m c m$ space group, while the DMA imposes the $C c m b$ space group. We observe that as the A-site cation becomes larger, the $\mathrm{Pb}-\mathrm{I}$ bond continuously elongates, expanding the volume of the perovskite cage, equivalent to exerting "negative pressure" on the perovskite structures. Optical studies and DFT calculations show the $\mathrm{Pb}-\mathrm{I}$ bond length elongation reduces overlap of the $\mathrm{Pb}$ s- and I p-orbitals and increases the optical bandgap, while $\mathrm{Pb}-\mathrm{I}-\mathrm{Pb}$ angles play a secondary role. Raman spectra show lattice softening with
\end{abstract}


increasing size of the A-site cation. These structural changes with enlarged A cations result in significant decreases in photoluminescence intensity and lifetime, consistent with a more pronounced nonradiative decay. Transient absorption microscopy (TAM) results suggest that the PL drop may derive from a higher concentration of traps or phonon-assisted nonradiative recombination. The results highlight that extending the range of Goldschmidt tolerance factors for $2 \mathrm{D}$ perovskites is achievable, enabling further tuning of the structure-property relationships in $2 \mathrm{D}$ perovskites.

Keyword: 2D materials, halide perovskites, Goldschmidt tolerance factor, A-site cation, bond elongation, photoluminescence, lattice softening. 


\section{Introduction}

Hybrid halide perovskites are emerging semiconductors with high mobility, long carrier lifetime and low trap density. ${ }^{1-2}$ The three-dimensional (3D) halide perovskites with corner-sharing octahedra have a general formula of $\mathrm{AMX}_{3}\left[\mathrm{~A}=\mathrm{Cs}^{+}, \mathrm{CH}_{3} \mathrm{NH}_{3}{ }^{+}(\mathrm{MA})\right.$, or $\mathrm{HC}\left(\mathrm{NH}_{2}\right)_{2}{ }^{+}(\mathrm{FA}) ; \mathrm{M}=$ $\left.\mathrm{Ge}^{2+}, \mathrm{Sn}^{2+}, \mathrm{Pb}^{2+} ; \mathrm{X}=\mathrm{Cl}^{-}, \mathrm{Br}^{-}, \mathrm{I}^{-}\right] \cdot{ }^{3-4}$ The A-site cation occupying/templating the cuboctahedral cages defined by the eight adjacent $\mathrm{Pb}$ atoms can be seen as "perovskitizers", and their choice is limited by the Goldschmidt tolerance factor, $t=\left(r_{A}+r_{X}\right) /\left[\sqrt{2}\left(r_{M}+r_{X}\right)\right]$, where $r_{A}, r_{M}$ and $r_{X}$ are the effective radii of $\mathrm{A}^{+}, \mathrm{M}^{2+}$ and $\mathrm{X}^{-}$ions, respectively. ${ }^{5-6} \mathrm{It}$ is only when the $t$ value is between 0.8 and 1 that perovskite phases are mostly observed. Cations giving $t$ larger than 1 or smaller than 0.8 are "forbidden" and instead stabilize non-perovskite phases. ${ }^{7}$ When $\mathrm{M}=\mathrm{Pb}^{2+}$ and $\mathrm{X}=\mathrm{I}^{-}$, the $t$ values of $\mathrm{Cs}^{+}$and FA are near the lower and upper limits of the ideal range, perovskite structures of $\mathrm{CsPbI}_{3}$ and $\mathrm{FAPbI}_{3}$ are metastable at room temperature. However for $\mathrm{M}=\mathrm{Sn}^{2+}, t$ values are closer to ideality, hence $\mathrm{CsSnI}_{3}$ and $\mathrm{FASnI}_{3}$ form stable perovskite structures. ${ }^{8}$

The equally important class of two-dimensional (2D) perovskites forms by incorporating an additional but larger organic cation which serve as spacers between the inorganic sheets. ${ }^{9-12}$ The most prominent are the Ruddlesden-Popper (RP) and Dion-Jacobson (DJ) phases with the formulas $\left(\mathrm{A}^{\prime}\right)_{2}(\mathrm{~A})_{n-1} \mathrm{~Pb}_{n} \mathrm{I}_{3 n+1}$ and $\mathrm{A}^{\prime} \mathrm{A}_{n-1} \mathrm{~Pb}_{n} \mathrm{I}_{3 n+1}$, respectively, where $\mathrm{A}, \mathrm{A}^{\prime}$ are cations (A' defining the organic spacers) and $n$ can reach values of up to $7 .{ }^{13-14}$ In this way, tremendous structural diversity can be rationally achieved in 2D perovskites especially in the thickness of the inorganic layers, providing materials which have properties of quantum well structures. ${ }^{9-12}$ The flexible spacer cations can also tolerate strain induced by the A-site cations larger than MA, ${ }^{15-16}$ as in $(\mathrm{BA})_{2}(\mathrm{FA}) \mathrm{Pb}_{2} \mathrm{I}_{7}$ and $(\mathrm{BA})_{2}(\mathrm{FA}) \mathrm{Pb}_{2} \mathrm{Br}_{7}(\mathrm{BA}=$ butylammonium $) .{ }^{17-18}$ Furthermore, it is possible for some $2 \mathrm{D}$ perovskites to incorporate larger cation, such as $(\mathrm{EA})_{2}(\mathrm{EA})_{2} \mathrm{~Pb}_{3} \mathrm{X}_{10}(\mathrm{EA}=$ ethylammonium) $(\mathrm{X}=\mathrm{Br}$ or $\mathrm{Cl}),{ }^{19}(\mathrm{IPA})_{2}(\mathrm{IPA}) \mathrm{Sn}_{2} \mathrm{I}_{7}(\mathrm{IPA}=\text { isopropylammonium })^{20}$ and $(\mathrm{BA})_{2}(\mathrm{EA})_{2} \mathrm{~Pb}_{3} \mathrm{I}_{10} \cdot{ }^{21-22} \mathrm{Fu}$ et al. ${ }^{16}$ reported the extension of Goldschmidt tolerance factor concept to 2D perovskites using hexylammonium (HA) as the spacer and formamidinium (FA), dimethylammonium (DMA), guanidinium (GA) and acetamidinium (AA) as A-site cations. However, among these compounds, only the single-crystal structure of $(\mathrm{HA})_{2}(\mathrm{GA}) \mathrm{Pb}_{2} \mathrm{I}_{7}$ was determined and a systematic study on how exactly the A-site cation affects the inorganic lattice and thus the optical properties of the 2D perovskites is still lacking. In order to better understand 
the structure-property relationship in 2D perovskites, especially optoelectronic properties such as the electronic bandgap and photoluminescence quantum yield (PLQY), it is crucial to solve and refine the precise single-crystal structure for all the compounds.

Here, we report the detailed structural evolution of the series $(B A)_{2}(A) \mathrm{Pb}_{2} \mathrm{I}_{7}(\mathrm{~A}=\mathrm{FA}, \mathrm{DMA}$ and GA) as a function of A cation size. Single-crystal X-ray diffraction shows elongation of the $\mathrm{Pb}-\mathrm{I}$ bonds with increasing the size of the A-site cation, which reduces the orbital overlap between $\mathrm{Pb}$ and I atoms and increases the optical bandgaps. This lattice expansion is a form of "negative pressure" exerted by the larger A-site cations. As the perovskite cages expand, the PL intensities and lifetimes decrease because of increased trap or phonon-mediated nonradiative recombination caused by lattice softening, as supported by the more diffuse low frequency Raman spectra. Our results highlight the remarkably soft and elastic nature of the 2D inorganic perovskite networks, which can respond continually to size changes in the A cation thereby extending the range of achievable Goldschmidt tolerance factor, rather than undergoing the dramatic structural transitions observed in the 3D perovskites.

\section{Experimental Section}

Starting Materials $\mathrm{PbO}$ (99.9\%), methylammonium chloride (98\%), formamidinium acetate (99\%), dimethylammonium chloride (99\%), guanidinium chloride (99\%), hydroiodic acid (57 wt $\%$ in $\mathrm{H}_{2} \mathrm{O}$, distilled, stabilized, 99.95\%), and hypophosphorous acid solution (50 wt \% in $\mathrm{H}_{2} \mathrm{O}$ ) were purchased from Sigma-Aldrich and used as received.

\section{Synthesis.}

$(\mathbf{B A})_{2}(\mathbf{M A}) \mathbf{P b}_{2} \mathbf{I}_{7}$ was synthesized as previously reported. ${ }^{23}$ The other three compounds were synthesized in a similar way with step-cooling to avoid the formation of light-yellow color nonperovskite phase.

$(\mathbf{B A})_{2}(\mathbf{F A}) \mathbf{P b}_{2} \mathbf{I}_{7}$. An amount of $1 \mathrm{mmol} \mathrm{PbO}(223 \mathrm{mg})$ and $0.5 \mathrm{mmol}$ formamidinium (FA) acetate $(52.1 \mathrm{mg})$ was dissolved in $1.5 \mathrm{~mL}$ concentrated HI solution under heating and stirring until boiling. $0.9 \mathrm{mmol}(89.1 \mu \mathrm{L})$ butylamine $(\mathrm{BA})$ was added to $0.25 \mathrm{~mL}$ of concentrated aqueous $\mathrm{H}_{3} \mathrm{PO}_{2}$ solution in a separate vial under stirring. The neutralized BA solution was added to the boiling HI solution under stirring until a clear yellow solution was obtained. Then the temperature was lowered to $125^{\circ} \mathrm{C}$ until red plate-shaped crystals started to precipitate out. Further decrease of the 
temperature to $80^{\circ} \mathrm{C}$ resulted in precipitation of most of the crystals within an hour. Then the hot plate was turned off and the solution was cooled to room temperature. After $30 \mathrm{~min}$, the product settled in the bottom of the vial and was isolated by suction filtration followed by drying on the filtration funnel for a further $30 \mathrm{~min}$. Yield: $228.5 \mathrm{mg}, 29.1 \%$ based on total $\mathrm{Pb}$.

(BA) (DMA) $_{2} \mathbf{P b}_{2} \mathbf{I}_{7}$. An amount of $1 \mathrm{mmol} \mathrm{PbO}(223 \mathrm{mg})$ and $0.5 \mathrm{mmol}$ dimethylammonium (DMA) chloride ( $40.8 \mathrm{mg}$ ) was dissolved in $1.75 \mathrm{~mL}$ concentrated HI solution under heating and stirring until boiling. $0.5 \mathrm{mmol}(49.6 \mu \mathrm{L}) \mathrm{BA}$ was added to $0.25 \mathrm{~mL}$ of concentrated aqueous $\mathrm{H}_{3} \mathrm{PO}_{2}$ solution in a separate vial under stirring. The neutralized BA solution was added to the boiling HI solution under stirring until a clear yellow solution was obtained. Then the temperature was lowered to $125^{\circ} \mathrm{C}$ until red plate-shaped crystals started to precipitate out. Further decrease of the temperature to $80{ }^{\circ} \mathrm{C}$ resulted in precipitation of most of the crystals within an hour. Then the hot plate was turned off and the solution was cooled to room temperature. After $30 \mathrm{~min}$, the product settled in the bottom of the vial and was isolated by suction filtration followed by drying on the filtration funnel for a further $30 \mathrm{~min}$. Yield: $165.4 \mathrm{mg}, 21.1 \%$ based on total $\mathrm{Pb}$.

(BA) $)_{\mathbf{2}}$ (GA) $\mathbf{P b}_{2} \mathbf{I}_{7}$. An amount of $1 \mathrm{mmol} \mathrm{PbO} \mathrm{(223} \mathrm{mg)} \mathrm{and} 0.5 \mathrm{mmol}$ guanidinium (GA) chloride $(47.8 \mathrm{mg}$ ) was dissolved in $1.5 \mathrm{~mL}$ concentrated $\mathrm{HI}$ solution under heating and stirring until boiling. $0.5 \mathrm{mmol}(49.6 \mu \mathrm{L}) \mathrm{BA}$ was added to $0.25 \mathrm{~mL}$ of concentrated aqueous $\mathrm{H}_{3} \mathrm{PO}_{2}$ solution in a separate vial under stirring. The neutralized BA solution was added to the boiling HI solution under stirring until a clear yellow solution was obtained. Then the temperature was lowered to $125^{\circ} \mathrm{C}$ until red plate-shaped crystals started to precipitate out. Further decrease of the temperature to $80^{\circ} \mathrm{C}$ resulted in precipitation of most of the crystals within an hour. Then the hot plate was turned off and the solution was cooled to room temperature. After $30 \mathrm{~min}$, the product settled in the bottom of the vial and was isolated by suction filtration followed by drying on the filtration funnel for a further $30 \mathrm{~min}$. Yield: $323.2 \mathrm{mg}, 42.8 \%$ based on total $\mathrm{Pb}$.

Steady-State and Time-Resolved Photoluminescence. Steady-state PL spectra were collected using a HORIBA LabRAM HR Evolution confocal Raman microscope. 473-nm laser was used to excite the samples at 50× magnification. Time-resolved photoluminescence spectra were acquired with a streak camera (Hamamatsu). The samples were excited at $400 \mathrm{~nm}$ under $2 \mathrm{kHz}$ repetition rate, which is obtained by frequency-doubling of the Ti:sapphire amplifier output at $800-\mathrm{nm}$ using 
a BBO crystal. A $435 \mathrm{~nm}$ long pass filter was used before the detection to block the excitation light.

Raman Spectroscopy. Low frequency Raman spectra were acquired using $660 \mathrm{~nm}$ laser excitation and the Raman signals were detected with a CCD camera. The measurements were performed in ambient conditions. The Raman spectra were acquired using a $20 \times$ objective under the parallel configuration (polarizations of the excitation laser and Raman scattered light are kept the same). Two notch filters were used to suppress the Rayleigh scattering, enabling the collection of Raman signals with wavenumber down to $10 \mathrm{~cm}^{-1}$. Details of the Raman setup used for the measurements have been reported elsewhere. ${ }^{24}$ The spectra were collected from $-150 \mathrm{~cm}^{-1}$ to $200 \mathrm{~cm}^{-1}$, and the samples were stable throughout the measurement.

\section{Results and Discussion}

\section{Synthesis}

We used the step-cooling method reported previously to grow red-color single crystals of $(\mathrm{BA})_{2}(\mathrm{~A}) \mathrm{Pb}_{2} \mathrm{I}_{7}[\mathrm{~A}=$ formamidinium $(\mathrm{FA})$, dimethylammonium (DMA) and guanidinium $(\mathrm{GA})] .{ }^{25-}$ 27 A 2:1 ratio of $\mathrm{PbO}$ and $\mathrm{A}$ cations was dissolved in concentrated $\mathrm{HI}$ solution under stirring and heated to a boil. In the case of $(\mathrm{BA})_{2}(\mathrm{DMA}) \mathrm{Pb}_{2} \mathrm{I}_{7}$ and $(\mathrm{BA})_{2}(\mathrm{GA}) \mathrm{Pb}_{2} \mathrm{I}_{7}$, half-stoichiometric ratio of BA (1:1:2 for BA, A cation and $\mathrm{PbO})$ was added to the solution to avoid formation of the $n=1$ phase (details in the Experimental Section), because the $n=1$ phase has the highest fraction of organic spacer, and higher concentration of BA favors lower layer-numbers. We also observed that there was no evidence for the existence of higher layer-number than $n=2$ when DMA and GA serve as A-site cations. For $(\mathrm{BA})_{2}(\mathrm{MA}) \mathrm{Pb}_{2} \mathrm{I}_{7}$ and $(\mathrm{BA})_{2}(\mathrm{FA}) \mathrm{Pb}_{2} \mathrm{I}_{7}, 70 \%$ and $90 \%$ of the stoichiometric ratio of BA was added, respectively. Using half-stoichiometric ratio (50\%) of BA in these cases led to higher layer-number phases forming concurrently. It is worth mentioning that with FA, darker crystals formed with low-energy absorption peaks; however, they seemed to be unstable and dissociated to $n=2$ and 3D phases within about half an hour, which suggests that the $n=2$ is a more thermodynamically stable phase. Direct cooling the solution to room temperature can result in the precipitation of yellow non-perovskite phase. Therefore, after a clear yellow solution was obtained under heating and stirring, the temperature of the hot plate was set to $125^{\circ} \mathrm{C}$, which is right below the boiling point of $\mathrm{HI}\left(127^{\circ} \mathrm{C}\right)$, so that the solution was still hot to prevent the formation of the yellow non-perovskite phases, while it was highly concentrated such that the 
red $n=2$ perovskite phases could still precipitate. Once the red crystals started to form, they served as seeds for further growth of the crystals until the precipitation was complete. We note that no crystals of other colors in the solution could be visually identified. The crystals were separated by vacuum filtration.

From the powder X-ray diffraction (PXRD) patterns in Figure 1a, we can clearly observe two characteristic peaks at $2 \theta \sim 4.5^{\circ}$ and $9^{\circ}$ that correspond to the $n=2$ phases. In the case of $(\mathrm{BA})_{2}(\mathrm{FA}) \mathrm{Pb}_{2} \mathrm{I}_{7}$ and $(\mathrm{BA})_{2}(\mathrm{DMA}) \mathrm{Pb}_{2} \mathrm{I}_{7}$, there are additional peaks because of the precipitation of the orange $n=1$ phase during the vacuum filtration. Since the crystals are big and the color of the $n=1$ (orange) and $n=2$ (red) phases are distinct from each other, they can be easily separated for further characterizations. The differential scanning calorimetry (DSC) measurements of all four samples are shown in Figure S1, which all exhibit distinctive phase transition(s) just below room temperature.

\section{Crystal structures.}

All structures were refined in both centrosymmetric and noncentrosymmetric space groups. As discussed previously, the structure of $(\mathrm{BA})_{2}(\mathrm{MA}) \mathrm{Pb}_{2} \mathrm{I}_{7}$ has been solved in both $\mathrm{Cmcm}$ and $\mathrm{Cc} 2 \mathrm{~m}$ space groups. ${ }^{23}$ The noncentrosymmetric space group is known to better reflect the local structure (e.g. configuration of the organic cation and hydrogen bonding) whereas the centrosymmetric space group better represents the averaged structure. Here, we want to focus on the average structure and how the A-site cation influences the inorganic part. Therefore, centrosymmetric space groups are used for all the discussions in the main text, and results for noncentrosymmetric space groups are shown in SI (Table S1, S2, S4 and Figure S3) for comparison purposes. It is worth noting that even though the noncentrosymmetric space groups give better refinement in terms of $\mathrm{R}$ values, the centrosymmetric ones result in significantly smaller estimated standard deviations (ESDs), thus believed to better represent the average structures. All the trends remain the same, however, regardless of the space group chosen. Both $(\mathrm{BA})_{2}(\mathrm{FA}) \mathrm{Pb}_{2} \mathrm{I}_{7}$ and $(\mathrm{BA})_{2}(\mathrm{GA}) \mathrm{Pb}_{2} \mathrm{I}_{7}$ crystallize in the same $\mathrm{Cmcm}$ space group (no 63) as $(\mathrm{BA})_{2}(\mathrm{MA}) \mathrm{Pb}_{2} \mathrm{I}_{7}$, while $(\mathrm{BA})_{2}(\mathrm{DMA}) \mathrm{Pb}_{2} \mathrm{I}_{7}$ adopts the $C \mathrm{cmb}$ space group, which is equivalent to the space group of $(\mathrm{BA})_{2}(\mathrm{MA})_{2} \mathrm{~Pb}_{3} \mathrm{I}_{10}(\mathrm{Cmca}$, no 64$)$ and can be transferred to $C m c a$ by symmetry operations (Table 1). The difference in space group ( $\mathrm{Cmcm}$ and $\mathrm{Cmcb}$ ) comes from the different symmetry elements, which is a glide plane between the two octahedral layers for $(\mathrm{BA})_{2}(\mathrm{DMA}) \mathrm{Pb}_{2} \mathrm{I}_{7}$, but a mirror plane 
crossing the spacer cation for $(\mathrm{BA})_{2}(\mathrm{MA}) \mathrm{Pb}_{2} \mathrm{I}_{7}$ and the other two structures (Figure $\left.1 \mathrm{~b}, \mathrm{c}\right)$. The organic spacer BA is restricted to the mirror plane parallel to the stacking direction in all the compounds. The $b$ and $c$ lattice parameters of the unit cell increase with larger A-site cation, however, the stacking $a$ axis does not follow the same trend, which will be discussed below.

The effective radius of the A-site cation increases as MA $<$ FA $<$ DMA $<$ GA, as shown in Table 2. The unit cell strain for the structures with larger A-site cation than MA originates from the significant variance in the $\mathrm{Pb}-\mathrm{I}$ bond lengths. As the effective radius of the A-site cation increases, the $\mathrm{Pb}-\mathrm{I}$ bonds in both the equatorial and axial directions become longer (Table 3), which is also reflected in the average $\mathrm{Pb}-\mathrm{I}$ bond lengths. The axial $\mathrm{Pb}-\mathrm{I}$ bond (denoted as $\mathrm{Pb}-\mathrm{I}_{\mathrm{ax}}$ bond) can be further divided into the external $\mathrm{Pb}-\mathrm{I}_{\mathrm{ax}}$ bond close to the spacer cation, and the internal $\mathrm{Pb}-\mathrm{I}_{\mathrm{ax}}$ bond next to the A-site cation (Figure 1d). The internal $\mathrm{Pb}-\mathrm{I}_{\mathrm{ax}}$ bond is the longest for all the structures, while the external ones are the shortest. Both the internal $\mathrm{Pb}-\mathrm{I}_{\mathrm{ax}}$ and the equatorial $\mathrm{Pb}-\mathrm{I}$ bond (denoted as $\mathrm{Pb}-\mathrm{I}_{\text {eq }}$ bond) lengths increase with the larger A-site cation (Figure 1, Table 3), which suggests that the perovskite cage expands to accommodate the large A-site cation. The cage expansion can be seen as a form of "negative chemical pressure" being exerted on the structure, in contrast to the studies under high-pressure, where there is cage contraction and the $\mathrm{Pb}-\mathrm{I}$ bond lengths decrease when increasing the pressure. ${ }^{28}$

The interlayer distance between the perovskite $\left[\mathrm{Pb}_{2} \mathrm{I}_{7}\right]^{3-}$ slabs as defined by planes crossing terminal iodine atoms is not a constant. In fact, the spacer cation is more compressed (interlayer d-spacing is smaller) in the cases of the larger A-site cations (Table 2). It is believed that by applying opposite compressive strain the spacer cations can balance the expansion of the perovskite cage and reduce the accumulated strain energy, ${ }^{15-16}$ leading to the an increase of the Goldschmidt tolerance factor range in 2D perovskites. ${ }^{16,29}$ Taking these factors into consideration, even though the unit cell volume (Table 1) varies only marginally with increasing size of A-site cation, the volume defined by eight adjacent $\mathrm{Pb}$ atoms does increase with the size of the A-site cation (Table 2), consistent with the exertion of negative pressure induced by the A cation size. The level of distortion for each individual octahedron can be defined by the distortion index (D) and bond angle variance $\left(\sigma^{2}\right)$ as calculated by the Vesta software ${ }^{30-31}$. The D and $\sigma^{2}$ are defined by equation (1) and (2), where $l_{\mathrm{av}}$ is the average $\mathrm{Pb}-\mathrm{I}$ bond distance and $\mathrm{l}_{\mathrm{i}}$ are the six individual bond distances, and $\theta_{\mathrm{i}}$ is the individual $\mathrm{I}-\mathrm{Pb}-\mathrm{I}$ angle. 
$D=\frac{1}{6} \sum_{i}^{6} \frac{\left|l_{i}-l_{a v}\right|}{l_{a v}}$

$\sigma^{2}=\sum_{i=1}^{12}\left(\theta_{i}-90\right)^{2} / 11$

The distortion index increases as the size of A-site cation becomes larger, with the DMA and GA compounds showing the largest distortion index. The MA compound has the smallest bond angle variance, followed by the FA and GA compounds, while the DMA compound has the largest bond angle variance (Table 2). The DMA structure has a different space group and symmetry elements than the other three. Instead of the mirror plane crossing the MA, FA and GA cations, the DMA cations are related via a glide plane (Figure $1 \mathrm{~b}, \mathrm{c}$ ). The axial $\mathrm{Pb}-\mathrm{I}$ bonds in the same octahedra tilt in opposite directions (left and right, Figure 1d) for MA, FA and GA, while they tilt in the same direction (both left or both right, Figure 1f) for DMA. Therefore, the I-Pb-I bond angles in the axial direction are smallest for DMA (Figure $1 \mathrm{~d}-\mathrm{g}$ ), and that is the reason why the DMA structure has a larger bond angle variance.

The $\mathrm{Pb}-\mathrm{I}-\mathrm{Pb}$ angles (Table 4) are similar for the four compounds. The MA compound has the smallest average $\mathrm{Pb}-\mathrm{I}-\mathrm{Pb}$ angle $\left(166.7^{\circ}\right)$, followed by the GA $\left(169.3^{\circ}\right)$ and $\mathrm{FA}\left(170.0^{\circ}\right)$ compounds, while the DMA compound has the largest average $\mathrm{Pb}-\mathrm{I}-\mathrm{Pb}$ angle $\left(171.1^{\circ}\right)$. The $\mathrm{Pb}-\mathrm{I}-\mathrm{Pb}$ angle can be further categorized into equatorial angle, which is parallel to the inorganic layer, and axial angle perpendicular to the layer. The large average $\mathrm{Pb}-\mathrm{I}-\mathrm{Pb}$ angle of the DMA compound originates mainly from the large axial angle, while the equatorial $\mathrm{Pb}-\mathrm{I}-\mathrm{Pb}$ angle, which may be more relevant to the charge transport direction in 2D perovskites, is the smallest.

Impact of increasing A-site cations on bandgap. The optical absorption spectra of the four compounds exhibit a high-energy absorption edge and a lower-energy exciton peak, Figure 2 . The bandgaps are estimated by extrapolating the high-energy slope to the imaginary axis parallel to the $x$ axis where the absorption edge is interrupted by the exciton peak. ${ }^{23,25}$ The corresponding optical bandgap energies are shown in Table 2, following the trend $E_{\mathrm{g}, \mathrm{DMA}}>E_{\mathrm{g}, \mathrm{GA}}>E_{\mathrm{g}, \mathrm{FA}}>E_{g, \mathrm{MA}}$. It is well known from previous studies, that $\mathrm{Pb}-\mathrm{I}-\mathrm{Pb}$ angle variation related to in-plane and outof-plane octahedra tilts are of prime importance to rationalize the bandgap energy in metal halide perovskites by changing the metal s- and halogen p-orbital overlap ${ }^{19}{ }^{32-33}$. However, the bond stretching and especially the variations of the $\mathrm{Pb}-\mathrm{I}$ distances also affect orbital overlap. To 
evaluate the influence of $\mathrm{Pb}-\mathrm{I}$ bond length on the electronic bandgap, we conducted density function theory (DFT) calculations for the structures reported here. Electronic structure calculations were performed using the experimental crystallographic structures except that hydrogen atom positions have been optimized. All compounds are direct bandgap semiconductors at the $\Gamma$ point (Figure 3). The dispersion along the $\Gamma-\mathrm{R}$ direction in the Brillouin zone is flat, which corresponds to the stacking direction $(a)$ in real space, indicative of 2D-like electronic structures. Regardless of the level of theory in use, the calculated electronic bandgaps follow the same trend with $E_{\mathrm{g}, \mathrm{DMA}}>E_{\mathrm{g}, \mathrm{GA}}>E_{\mathrm{g}, \mathrm{FA}}>E_{\mathrm{g}, \mathrm{MA}}$. The calculated bandgaps are $2.60 \mathrm{eV}, 2.55 \mathrm{eV}, 2.54 \mathrm{eV}$ and $2.48 \mathrm{eV}$, respectively, at the Heyd, Scuseria and Ernzerhof + spin-orbit coupling level of theory with $73 \%$ of Fock exchange. ${ }^{34} \mathrm{We}$ further checked the partial density of states (PDOS) using DFT calculations, that intrinsic band structures are not deeply modified by A-site cations (Figure S2). In particular, the respective weights of $\mathrm{Pb}$ s- and I p-orbitals at the top of the valence band are only slightly modified by the substitution.

The band structure calculations for the noncentrosymmetric space groups are also shown in SI (Table S4, Figure S3). The bandgaps show the same trend as those calculated in the centrosymmetric space groups (Table S3, S4).

By inspecting the crystal structure, we can see that in the present series the octahedral tilts $(\mathrm{Pb}-\mathrm{I}-\mathrm{Pb}$ angle) remain similar whereas the $\mathrm{Pb}-\mathrm{I}$ bonds undergo significant length variations, depending on the A-site cation. To focus on the impact of bond length variation on the electronic bandgap energy, we built a simplified model structure " $\mathrm{Cs}_{3} \mathrm{~Pb}_{2} \mathrm{I}_{7}$ " (Figure 4a) and computed the bandgap energies considering a range of bond lengths consistent with the present crystal structures. In order to isolate the effect of $\mathrm{Pb}-\mathrm{I}$ bond lengths, all octahedral connections were kept as undistorted with $180^{\circ} \mathrm{Pb}-\mathrm{I}-\mathrm{Pb}$ angles. As discussed in the crystal structure part, the axial $\mathrm{Pb}-\mathrm{I}$ bond can be further divided into external and internal ones. Since the external $\mathrm{Pb}-\mathrm{I}_{\mathrm{ax}}$ contributes less to the VBM and CBM spinor densities, ${ }^{35}$ we only consider the equatorial $\mathrm{Pb}-\mathrm{I}\left(\mathrm{d}_{\mathrm{Pb}-\mathrm{I}_{\mathrm{eq}}}\right)$ and the internal $\mathrm{Pb}-\mathrm{I}_{\mathrm{ax}}\left(\mathrm{d}_{\mathrm{Pb}-\mathrm{I}_{\mathrm{ax}-\text { int }}}\right)$ bond lengths, all external $\mathrm{Pb}-\mathrm{I}_{\mathrm{ax}}\left(\mathrm{d}_{\mathrm{Pb}-\mathrm{I}_{\mathrm{ax}-\mathrm{ex}}}\right)$ bond lengths have been fixed at $3.1 \AA$ (Figure 4a). A vacuum slab of $25 \AA$ was introduced between the layers. To obtain a mapping of the electronic bandgap, the $d_{P b-I_{a x}-\text { int }}$ and $d_{P b-I_{e q}}$ bond lengths were varied from 3.1 to $3.4 \AA(0.1 \AA$ steps $)$ and 3.1 to $3.3 \AA(0.025 \AA$ steps $)$, respectively, and the corresponding bandgap vs bond length map is shown in Figure $4 \mathrm{~b}$. 
As shown in Figure 4b, the bandgaps increase with increasing $\mathrm{Pb}-\mathrm{I}$ bond lengths, following the experimental trend that $E_{\mathrm{g}, \mathrm{GA}}>E_{\mathrm{g}, \mathrm{FA}}>E_{g, \mathrm{MA}}$. This simplified model predicts that $(\mathrm{BA})_{2}(\mathrm{GA}) \mathrm{Pb}_{2} \mathrm{I}_{7}$ has the widest bandgap among the four compounds, while DFT calculations on the real structures (Figure 3) leads to $E_{\mathrm{g}, \mathrm{DMA}}>E_{\mathrm{g}, \mathrm{GA}}$ (also confirmed experimentally, Figure 2). This is because the 2D mapping does not take into consideration additional octahedral distortions and deviation of $\mathrm{Pb}-\mathrm{I}-\mathrm{Pb}$ angles from $180^{\circ}$. When the bond lengths are similar, the $\mathrm{Pb}-\mathrm{I}-\mathrm{Pb}$ angles still play the role in affecting the bandgaps. It turns out that $(\mathrm{BA})_{2}(\mathrm{DMA}) \mathrm{Pb}_{2} \mathrm{I}_{7}$ has the smallest equatorial $\mathrm{Pb}-\mathrm{I}-\mathrm{Pb}$ angle among the series (Table 4 ), which means the octahedra are more significantly tilted in the planes of the 2D layer that in turn increases the bandgap energy. This suggests that for this series of layered perovskites the $\mathrm{Pb}-\mathrm{I}$ bond lengths are the main factors tuning the bandgap energy and the equatorial $\mathrm{Pb}-\mathrm{I}-\mathrm{Pb}$ angles exert a secondary effect. Meanwhile, both these structural components cooperate to minimize the strain energy in layered perovskites. ${ }^{15}$ Other researchers have observed similar trend of bandgap blueshift for larger A-site cations in the colloidal nanoplates. ${ }^{36}$ It is worth mentioning that the trend of the bulk and colloidal systems is slightly different. The size dependence of absorption peak for the 2D perovskite nanoplates follows the same trend as the 3D bulk perovskites $\mathrm{APbI}_{3}\left(\mathrm{~A}=\mathrm{Cs}^{+}, \mathrm{MA}\right.$ and $\left.\mathrm{FA}\right)$ that $\mathrm{E}_{\mathrm{gCs}}>\mathrm{E}_{\mathrm{gMA}}>\mathrm{E}_{\mathrm{gFA}}$, while for the $2 \mathrm{D}$ bulk perovskites, $\mathrm{E}_{\mathrm{gMA}}<\mathrm{E}_{\mathrm{gFA}}<\mathrm{E}_{\mathrm{gGA}}$.

Trends in PL and lattice softening. All compounds exhibit photoluminescence at room temperature, with the PL peak positions following the same trend as the bandgap (Figure 5a), consistent with the trends derived from electronic band structure calculations and the optical absorption spectra. It is worth noting that the intensity of the PL peaks drops as the size of the Asite cation increases (Figure 5b). The PL quantum yield (PLQY, $\phi)$ is defined by the equation $\phi=$ $\frac{k_{r}}{k_{r}+k_{n}}$, where $k_{\mathrm{r}}$ and $k_{\mathrm{n}}$ are the rate constant of the radiative and nonradiative decay, respectively. ${ }^{37-}$ 39 Because of the similar dielectric environments of the compounds, the exciton binding energy and the radiative decay rate are generally expected to be similar. The observed decrease of the PL intensity, however, suggests a higher nonradiative decay rate in the larger A-site cation compounds, which is also confirmed by the time-resolved PL (TRPL) measurement (Figure 5c). The TRPL plots are fitted with two exponential decays, and the PL lifetime values summarized in Table S5. The timescale of the PL lifetimes varies as $\tau_{\mathrm{avg}, \mathrm{MA}}>\tau_{\mathrm{avg}, \mathrm{FA}}>\tau_{\mathrm{avg} \text {, DMA }}>\tau_{\mathrm{avg}, \mathrm{GA}}$ which shows that as the size of the A-site cation increases, the PL lifetime decreases, matching the trend of the PL 
intensity. We note that we measured the TRPL using the 2 ns window of a streak camera, which focuses on the intrinsic exciton recombination. Longer-lived processes which are caused by extrinsic effects may also exist based on the long tail of the PL decay curve, but the work aimed at understanding the origins of this is outside the scope of the manuscript.

The decreasing trend in PL lifetime may come from more defect states that trap the excitons in perovskites incorporating larger A-site cations, which can serve as recombination centers and quench the PL. ${ }^{40}$ At low photon fluence, the PLQY is limited by the charge trapping pathway, ${ }^{41}$ which is the process discussed here. It has been reported that 2D perovskite with larger A-site cation, $(\mathrm{BA})_{2}(\mathrm{EA})_{2} \mathrm{~Pb}_{3} \mathrm{I}_{10}$, exhibits higher defect densities than $(\mathrm{BA})_{2}(\mathrm{MA})_{2} \mathrm{~Pb}_{3} \mathrm{I}_{10}$, and shorter $\mathrm{PL}$ lifetime. ${ }^{42}$ At high fluence, the trap states are predominantly filled and Auger recombination or exciton-exciton annihilation is the dominant channel for the nonradiative loss. ${ }^{41,43-44}$ The excitonexciton annihilation is expected to be enhanced in the 2D perovskites. Nevertheless, our transient absorption measurements reveal that the exciton-exciton annihilation rates appear slower in the structures with large A cations, as will be discussed later.

The $6 \mathrm{~s}^{2}$ lone pairs that dominate the top of the VBM play an important role in physical properties of halide perovskites. These lone pairs are crystallographically hidden (delocalized) in 3D perovskites, and only exhibit local distortion upon thermal expansion as they struggle to achieve stereochemical expression. ${ }^{45}$ This distorts the octahedral coordination geometry as the $\mathrm{Pb}$ atoms move slightly off-center possibly in random directions and in a dynamic way. Therefore, these lone pairs may be more localized in these $2 \mathrm{D}$ perovskites at room temperature because of the expansion of $\mathrm{Pb}-\mathrm{I}$ bonds. The stereochemical activity can be characterized by the large distortion index and bond angle variance as discussed above. Our hypothesis is that as the size of the A-site cation increases, the $\mathrm{Pb}$-I bonds get elongated and the inorganic framework becomes "loose" and more deformable. Thus, the lone pairs are more statically expressed and result in stronger lattice anharmonicity. A less rigid structure is easier to form defects and the optical phonon frequency is expected to decrease since it is directly proportional to the chemical bond strength, and this trend is associated with lattice "softness".

The lattice anharmonicity and softness can be probed via the low-frequency Raman spectral characterization (Figure 6). We used a laser with $660 \mathrm{~nm}$ wavelength, which is below the bandgaps of the compounds, to excite the materials in the transparency region and avoid undesirable PL 
background. As shown in Figure 6, the Raman spectra of all four compounds consist of broad quasielastic central peaks around $0 \mathrm{~cm}^{-1}$, which are diffuse, and composed of spectral continuum underlying broad Raman transitions. The broad central peaks are signatures of anharmonic, highly dynamic and fluctuating structures. ${ }^{46-49}$ Also seen in $\mathrm{MAPbI}_{3}, \mathrm{MAPbBr}_{3}$ and $\mathrm{CsPbBr}_{3}$ perovskites, this type of room temperature Raman spectra is known to be associated with soft distortive lattices and interestingly similar to those of fluids. ${ }^{46-47}$ Besides the broad peaks, there are also some distinct low-frequency peaks at $25 \mathrm{~cm}^{-1}$ and $45 \mathrm{~cm}^{-1}$ for $(\mathrm{BA})_{2}(\mathrm{MA}) \mathrm{Pb}_{2} \mathrm{I}_{7}$, which may correspond to the bending modes of $\left[\mathrm{PbI}_{6}\right]^{4-}$ octahedra. ${ }^{47,}{ }^{50-51}$ As the size of the A-site cation increases, there are two clear observations. First, the peak positions in the spectra shift to lower frequency (Figure 6). Since the frequency is directly proportional to the bond strength, it is expected that longer bonds result in lower energy for the optical phonons. Second, the spectra become more diffuse since the broad background associated with dynamic disorder emerges, which suggests that the structure becomes more anharmonic as A-site cation size increases, indicating a softer lattice. This can be rationalized by the expression of the $6 s^{2}$ lone pair in the loosely connected structure, which tends to become localized, acting as a lever of perturbation of the octahedral coordination environment. ${ }^{45}$ This perturbation is likely the origin of the enhanced disorder observed as the size of the A-site cation increases.

Trend in Carrier Dynamics. Many-body exciton-exciton annihilation in strongly excited low dimensional semiconductors represents an important nonradiative loss path that limits the efficiency in lasers and LEDs. The annihilation is a process when an exciton recombines nonradiatively and transfers the energy to another exciton, which is analogous to Auger recombination for free carriers. Exciton-exciton annihilation is expected to be efficient in 2D perovskites due to the strong many-body interactions and large exciton binding energies (for example up to $200 \mathrm{meV}$ in $\left.(\mathrm{BA})_{2}(\mathrm{MA}) \mathrm{Pb}_{2} \mathrm{I}_{7}\right)$ at room temperature. Under low excitation power density at which the TRPL is measured, there are still trap states so that the PL decays are nonexponential because of trap-assisted recombination, whereas under high excitation power density, the exciton-exciton annihilation dominates recombination dynamics. ${ }^{43-44}$

To better understand the exciton annihilation dynamics in these materials, we performed ultrafast transient absorption microscopy measurements on exfoliated crystals under a high excitation power density. The pump fluence was $\sim 120 \mu \mathrm{J} \mathrm{cm}^{-2}$, corresponding to a carrier density of $\sim 10^{12}$ 
$\mathrm{cm}^{-2}$, below the Mott density $\left(\sim 10^{14} \mathrm{~cm}^{-2}\right){ }^{44}$ The absorption spectra of the exfoliated crystals (Figure S4) match well the ones of bulk crystals obtained by the diffuse reflectance UV-vis measurements. As shown in Figure 7, the 2D transient absorption (TA) map exhibits a groundstate bleaching (GSB) feature (blue color) at the optical bandgap and two photo-induced absorption (PIA) (red colors) above and below the optical bandgap. There are also weak bleaching features (light-blue color) below the optical bandgap for the MA, FA and GA compounds (purple decay trace in Figure S5). The dynamics of the four features for the first $6 \mathrm{ps}$ is shown in Figure S5. The GSB rises at sub-picosecond timescale due to the fast band-edge population ${ }^{52}$ and then goes through a slow decay process, lasting in the hundreds of ps, which is associated with the excitonexciton annihilation given the high fluence used in the measurement. ${ }^{39}$

The TA features are markedly similar to those of previous studies under lower excitation power densities, confirming that the excitons remain the main excited-state species here (i.e. below the Mott transition). We then model the decay kinetics of the bleaching peak using the rate equation $\frac{d n(t)}{d t}=k n(t)^{2}$, as expected for the exciton-exciton annihilation process, in which $n(t)$ is the exciton density and $k$ is the rate constant for the exciton annihilation. In the linear region we performed the measurement, the TA signal should be proportional to exciton density $(\Delta T \propto n(t))$. Therefore, to fit the rate constant in $\frac{1 d n(t)}{n(t)^{2} d t}=k$, we plotted the $1 / \Delta T \sim t$ curve (Figure 7e), the slope divided by the initial carrier density (Table S6) gives the rate constant. The annihilation rate constants are calculated to be $1.7 \times 10^{-2}, 3.5 \times 10^{-2}, 2.8 \times 10^{-3}$, and $4.4 \times 10^{-3} \mathrm{~cm}^{2} \mathrm{~s}^{-1}$ for $(\mathrm{BA})_{2}(\mathrm{MA}) \mathrm{Pb}_{2} \mathrm{I}_{7},(\mathrm{BA})_{2}(\mathrm{FA}) \mathrm{Pb}_{2} \mathrm{I}_{7},(\mathrm{BA})_{2}(\mathrm{DMA}) \mathrm{Pb}_{2} \mathrm{I}_{7}$ and $(\mathrm{BA})_{2}(\mathrm{GA}) \mathrm{Pb}_{2} \mathrm{I}_{7}$, respectively. For comparison, the exciton annihilation rate is $1.1 \times 10^{-4} \mathrm{~cm}^{2} \mathrm{~s}^{-1}$ for $(\mathrm{PEA})_{2}(\mathrm{MA}) \mathrm{Pb}_{2} \mathrm{I}_{7}(\mathrm{PEA}=$ phenethylammonium $)^{43}$ and $\sim 2 \times 10^{-2} \mathrm{~cm}^{2} \mathrm{~s}^{-1}$ for $(\mathrm{BA})_{2}(\mathrm{MA}) \mathrm{Pb}_{2} \mathrm{I}_{7}{ }^{44}$. Because the annihilation rate sets an upper limit on the density of injected charges, for the same spacer cation such as BA, the even smaller values in the structures with larger A-site cations than MA indicate they could be more promising candidates for lasing. ${ }^{53}$ Moreover, the results further support that the PL drop is mainly due to the increased trap or phonon-assisted nonradiative recombination rather than the exciton-exciton annihilation that manifests in 2D perovskites. Even though the role of surface and edges have not been ruled out, they are less likely to be responsible for the PL quenching. 
The main GSB peak becomes broader with increasing size of A-site cation (Figure 7f), and so are the absorption (Figure S4) and the emission peak (Figure 5a) (Table S7). The broadening originates from enhanced dynamic disorder, which can be correlated to the larger octahedral distortion of those structures. The below-bandgap bleaching was previously assigned to the trap states below the bandgap. ${ }^{54}$ These traps may not come from common chemical defects, but from the trapping of the band-edge exciton through electron-phonon coupling. ${ }^{54}$ Strong electron-phonon coupling has been assumed to play a role for the sub bandgap states in $2 \mathrm{D}$ perovskites. ${ }^{55}$

\section{Conclusions}

In $2 \mathrm{D}$ perovskites, the choice of the A-site perovskitizer cations is not entirely limited by the socalled Goldschmidt tolerance factor. The stabilizing effect of the spacer cations makes it possible to tolerate larger A-site cations as perovskitizers. By solving the single-crystal structures of $(\mathrm{BA})_{2}(\mathrm{MA}) \mathrm{Pb}_{2} \mathrm{I}_{7},(\mathrm{BA})_{2}(\mathrm{FA}) \mathrm{Pb}_{2} \mathrm{I}_{7},(\mathrm{BA})_{2}(\mathrm{DMA}) \mathrm{Pb}_{2} \mathrm{I}_{7}$ and $(\mathrm{BA})_{2}(\mathrm{GA}) \mathrm{Pb}_{2} \mathrm{I}_{7}$, we have proven that the relatively large DMA and GA can serve as the A-site cation of 2D perovskites despite the fact that they are too large to formally satisfy the Goldschmidt rule. As the size of the A-site cations across these compounds increases, the $\mathrm{Pb}-\mathrm{I}$ bonds are elongated, which reduces the orbital overlap of $\mathrm{Pb}$ s- and I p-orbitals, thus decreasing the electronic bandwidths and increasing the bandgaps, as confirmed by DFT calculations. The expanded cage size essentially equals to a "negative chemical pressure" applied to the 2D perovskite structure. This increases the local distortions of the $\mathrm{PbI}_{6}$ coordination environment and leads to a decrease of PL intensity and shortening of PL lifetime. The expanded cages also result in soft and anharmonic lattices, as supported by Raman spectra. Exciton-exciton annihilation processes occur in these systems with the rates being slower in the structures with larger A cations.

Our study suggests that increasing the size of the A-site cation can lead to $\mathrm{Pb}-\mathrm{I}$ bond elongation, bandgap blueshift, lattice softening and PL quenching, showing that the A-site cation has powerful tunability over the property of 2D perovskites. Finally, there is a long-standing debate on the role of the A-site cations (organic vs inorganic, polar vs nonpolar) in the outstanding properties of halide perovskites. ${ }^{56-57}$ While MA, FA and DMA are polar cations, the GA cation is nonpolar. There are many reports on how the A-site cation may influence the properties of the 3D perovskites, ${ }^{48-49,} 56-57$ such as carrier dynamics, ${ }^{48,} 57$ local ferroelectric domains, ${ }^{49}$, 56 Rashba splitting, ${ }^{58}$ and localizing conduction and valence band edges in spatially separated regions ${ }^{56}$. 
However, agreement still has not been reached and very few studies have been done on 2D perovskites. Our work presents more choices of A-site cations for 2D perovskites with different dipole moments and provides a set of model systems to study the effect of A-site cation on the property of perovskites. This study improves our understanding of the structure-property relationship of 2D perovskites and could help future design of more optimal materials for specific optoelectronic applications.

\section{Associated content}

\section{Supporting information}

More experimental details for powder X-ray diffraction, absorption spectroscopy, transient absorption microscopy, crystallographic details and DFT calculations.

X-ray crystallographic data of $(\mathrm{BA})_{2}(\mathrm{FA}) \mathrm{Pb}_{2} \mathrm{I}_{7}$.

X-ray crystallographic data of $(\mathrm{BA})_{2}(\mathrm{DMA}) \mathrm{Pb}_{2} \mathrm{I}_{7}$.

X-ray crystallographic data of $(\mathrm{BA})_{2}(\mathrm{GA}) \mathrm{Pb}_{2} \mathrm{I}_{7}$.

\section{Author information}

\section{Corresponding Author}

*m-kanatzidis@northwestern.edu

\section{Present Address}

Peijun Guo: Department of Chemical and Environmental Engineering, Yale University, 9 Hillhouse Avenue, New Haven, Connecticut 06520, United States.

\section{Notes}

The authors declare no competing financial interest.

\section{Acknowledgements}

At Northwestern University this work is mainly supported by the Department of Energy, Office of Science, Basic Energy Sciences, under Grant No. SC0012541 (synthesis, structure, and physical 
property characterization). Transient absorption microscopy measurement was provided in part by the Enabling Quantum Leap program; an NSF EAGER grant under award number DMR-1838507. DFT calculations were performed at Institut FOTON and the work was granted access to the HPC resources of TGCC/CINES/IDRIS under the allocation 2019-A0060906724 made by GENCI. J.E acknowledges the financial support from the Institut Universitaire de France. Raman measurements were performed at GeoSoilEnviroCARS (The University of Chicago, Sector 13), Advanced Photon Source (APS), Argonne National Laboratory. GeoSoilEnviroCARS is supported by the National Science Foundation - Earth Sciences (EAR - 1634415). The Raman system acquisition was supported by the NSF MRI proposal (EAR-1531583). This work was performed, in part, at the Center for Nanoscale Materials, a U.S. Department of Energy Office of Science User Facility, and supported by the U.S. Department of Energy, Office of Science, under Contract No. DE-AC02-06CH11357.This work made use of the SPID (confocal microscopy) facilities of Northwestern University's NUANCE Center, which has received support from the Soft and Hybrid Nanotechnology Experimental Resource (NSF ECCS1542205), the Materials Research Science and Engineering Centers (NSF DMR-1720139), the International Institute for Nanotechnology (IIN), the Keck Foundation, and the State of Illinois through the IIN. 


\section{References}

1. Xing, G.; Mathews, N.; Sun, S.; Lim, S. S.; Lam, Y. M.; Grätzel, M.; Mhaisalkar, S.; Sum, T. C., Long-Range Balanced Electron- and Hole-Transport Lengths in Organic-Inorganic $\mathrm{CH}_{3} \mathrm{NH}_{3} \mathrm{PbI}_{3}$. Science 2013, 342 (6156), 344-347.

2. Dong, Q.; Fang, Y.; Shao, Y.; Mulligan, P.; Qiu, J.; Cao, L.; Huang, J., Electron-hole diffusion lengths $>175 \mu \mathrm{m}$ in solution-grown $\mathrm{CH}_{3} \mathrm{NH}_{3} \mathrm{PbI}_{3}$ single crystals. Science 2015, 347 (6225), 967-970.

3. Stoumpos, C. C.; Kanatzidis, M. G., The Renaissance of Halide Perovskites and Their Evolution as Emerging Semiconductors. Acc. Chem. Res. 2015, 48 (10), 2791-2802.

4. Stoumpos, C. C.; Kanatzidis, M. G., Halide Perovskites: Poor Man's High-Performance Semiconductors. Adv. Mater. 2016, 28 (28), 5778-5793.

5. Kieslich, G.; Sun, S.; Cheetham, A. K., Solid-state principles applied to organicinorganic perovskites: new tricks for an old dog. Chem. Sci. 2014, 5 (12), 4712-4715.

6. Travis, W.; Glover, E. N. K.; Bronstein, H.; Scanlon, D. O.; Palgrave, R. G., On the application of the tolerance factor to inorganic and hybrid halide perovskites: a revised system. Chem. Sci. 2016, 7 (7), 4548-4556.

7. Fu, Y.; Zhu, H.; Chen, J.; Hautzinger, M. P.; Zhu, X. Y.; Jin, S., Metal halide perovskite nanostructures for optoelectronic applications and the study of physical properties. Nat. Rev. Mater. 2019, 4 (3), 169-188.

8. $\quad$ Stoumpos, C. C.; Malliakas, C. D.; Kanatzidis, M. G., Semiconducting Tin and Lead Iodide Perovskites with Organic Cations: Phase Transitions, High Mobilities, and Near-Infrared Photoluminescent Properties. Inorg. Chem. 2013, 52 (15), 9019-9038.

9. Saparov, B.; Mitzi, D. B., Organic-Inorganic Perovskites: Structural Versatility for Functional Materials Design. Chem. Rev. 2016, 116 (7), 4558-4596.

10. Smith, M. D.; Connor, B. A.; Karunadasa, H. I., Tuning the Luminescence of Layered Halide Perovskites. Chem. Rev. 2019, 119 (5), 3104-3139.

11. Mao, L.; Stoumpos, C. C.; Kanatzidis, M. G., Two-Dimensional Hybrid Halide Perovskites: Principles and Promises. J. Am. Chem. Soc. 2019, 141 (3), 1171-1190.

12. Katan, C.; Mercier, N.; Even, J., Quantum and Dielectric Confinement Effects in LowerDimensional Hybrid Perovskite Semiconductors. Chem. Rev. 2019, 119 (5), 3140-3192.

13. Soe, C. M. M.; Nagabhushana, G. P.; Shivaramaiah, R.; Tsai, H.; Nie, W.; Blancon, J.-C.; Melkonyan, F.; Cao, D. H.; Traoré, B.; Pedesseau, L.; Kepenekian, M.; Katan, C.; Even, J.; Marks, T. J.; Navrotsky, A.; Mohite, A. D.; Stoumpos, C. C.; Kanatzidis, M. G., Structural and thermodynamic limits of layer thickness in 2D halide perovskites. Proc. Natl. Acad. Sci. 2019, $116(1), 58-66$.

14. Mao, L.; Kennard, R. M.; Traore, B.; Ke, W.; Katan, C.; Even, J.; Chabinyc, M. L.; Stoumpos, C. C.; Kanatzidis, M. G., Seven-Layered 2D Hybrid Lead Iodide Perovskites. Chem 2019, 5 (10), 2593-2604.

15. Kepenekian, M.; Traore, B.; Blancon, J.-C.; Pedesseau, L.; Tsai, H.; Nie, W.; Stoumpos, C. C.; Kanatzidis, M. G.; Even, J.; Mohite, A. D.; Tretiak, S.; Katan, C., Concept of Lattice Mismatch and Emergence of Surface States in Two-dimensional Hybrid Perovskite Quantum Wells. Nano Lett. 2018, 18 (9), 5603-5609.

16. Fu, Y.; Hautzinger, M. P.; Luo, Z.; Wang, F.; Pan, D.; Aristov, M. M.; Guzei, I. A.; Pan, A.; Zhu, X.; Jin, S., Incorporating Large A Cations into Lead Iodide Perovskite Cages: Relaxed Goldschmidt Tolerance Factor and Impact on Exciton-Phonon Interaction. ACS Cent. Sci. 2019, 5 (8), 1377-1386. 
17. Paritmongkol, W.; Dahod, N. S.; Stollmann, A.; Mao, N.; Settens, C.; Zheng, S.-L.; Tisdale, W. A., Synthetic Variation and Structural Trends in Layered Two-Dimensional Alkylammonium Lead Halide Perovskites. Chem. Mater. 2019, 31 (15), 5592.

18. Li, L.; Shang, X.; Wang, S.; Dong, N.; Ji, C.; Chen, X.; Zhao, S.; Wang, J.; Sun, Z.; Hong, M.; Luo, J., Bilayered Hybrid Perovskite Ferroelectric with Giant Two-Photon Absorption. J. Am. Chem. Soc. 2018, 140 (22), 6806-6809.

19. Mao, L.; Wu, Y.; Stoumpos, C. C.; Traore, B.; Katan, C.; Even, J.; Wasielewski, M. R.; Kanatzidis, M. G., Tunable White-Light Emission in Single-Cation-Templated Three-Layered 2D Perovskites $\left(\mathrm{CH}_{3} \mathrm{CH}_{2} \mathrm{NH}_{3}\right)_{4} \mathrm{~Pb}_{3} \mathrm{Br}_{10-\mathrm{x}} \mathrm{Cl}_{\mathrm{x}}$. J. Am. Chem. Soc. 2017, 139 (34), 11956-11963.

20. Stoumpos, C. C.; Mao, L.; Malliakas, C. D.; Kanatzidis, M. G., Structure-Band Gap Relationships in Hexagonal Polytypes and Low-Dimensional Structures of Hybrid Tin Iodide Perovskites. Inorg. Chem. 2017, 56 (1), 56-73.

21. Han, S.; Liu, X.; Liu, Y.; Xu, Z.; Li, Y.; Hong, M.; Luo, J.; Sun, Z., High-Temperature Antiferroelectric of Lead Iodide Hybrid Perovskites. J. Am. Chem. Soc. 2019, 141 (32), 1247012474 .

22. Fu, Y.; Jiang, X.; Li, X.; Traore, B.; Spanopoulos, I.; Katan, C.; Even, J.; Kanatzidis, M. G.; Harel, E., Cation Engineering in Two-Dimensional Ruddlesden-Popper Lead Iodide Perovskites with Mixed Large A-Site Cations in the Cages. J. Am. Chem. Soc. 2020, 142 (8), 4008-4021.

23. Stoumpos, C. C.; Cao, D. H.; Clark, D. J.; Young, J.; Rondinelli, J. M.; Jang, J. I.; Hupp, J. T.; Kanatzidis, M. G., Ruddlesden-Popper Hybrid Lead Iodide Perovskite 2D Homologous Semiconductors. Chem. Mater. 2016, 28 (8), 2852-2867.

24. Holtgrewe, N.; Greenberg, E.; Prescher, C.; Prakapenka, V.; Goncharov, A., Advanced integrated optical spectroscopy system for diamond anvil cell studies at GSECARS. High Pressure Res. 2019, 39, 1-14.

25. Li, X.; Hoffman, J.; Ke, W.; Chen, M.; Tsai, H.; Nie, W.; Mohite, A. D.; Kepenekian, M.; Katan, C.; Even, J.; Wasielewski, M. R.; Stoumpos, C. C.; Kanatzidis, M. G., TwoDimensional Halide Perovskites Incorporating Straight Chain Symmetric Diammonium Ions, $\left(\mathrm{NH}_{3} \mathrm{C}_{\mathrm{m}} \mathrm{H}_{2 \mathrm{~m}} \mathrm{NH}_{3}\right)\left(\mathrm{CH}_{3} \mathrm{NH}_{3}\right)_{\mathrm{n}-1} \mathrm{~Pb}_{\mathrm{n}} \mathrm{I}_{3 \mathrm{n}+1}(\mathrm{~m}=4-9 ; \mathrm{n}=1-4)$. J. Am. Chem. Soc. 2018, 140 (38), 12226-12238.

26. Li, X.; Ke, W.; Traoré, B.; Guo, P.; Hadar, I.; Kepenekian, M.; Even, J.; Katan, C.; Stoumpos, C. C.; Schaller, R. D.; Kanatzidis, M. G., Two-Dimensional Dion-Jacobson Hybrid Lead Iodide Perovskites with Aromatic Diammonium Cations. J. Am. Chem. Soc. 2019, 141 (32), 12880-12890.

27. Li, X.; He, Y.; Kepenekian, M.; Guo, P.; Ke, W.; Even, J.; Katan, C.; Stoumpos, C. C.; Schaller, R. D.; Kanatzidis, M. G., Three-dimensional Lead Iodide Perovskitoid Hybrids with High X-ray Photoresponse. J. Am. Chem. Soc. 2020, 142 (14), 6625-6637.

28. Liu, G.; Gong, J.; Kong, L.; Schaller, R. D.; Hu, Q.; Liu, Z.; Yan, S.; Yang, W.;

Stoumpos, C. C.; Kanatzidis, M. G.; Mao, H.-k.; Xu, T., Isothermal pressure-derived metastable states in 2D hybrid perovskites showing enduring bandgap narrowing. Proc. Natl. Acad. Sci. 2018, 115 (32), 8076-8081.

29. Fu, Y.; Wu, T.; Wang, J.; Zhai, J.; Shearer, M. J.; Zhao, Y.; Hamers, R. J.; Kan, E.; Deng, K.; Zhu, X. Y.; Jin, S., Stabilization of the Metastable Lead Iodide Perovskite Phase via Surface Functionalization. Nano Lett. 2017, 17 (7), 4405-4414.

30. Robinson, K.; Gibbs, G. V.; Ribbe, P. H., Quadratic Elongation: A Quantitative Measure of Distortion in Coordination Polyhedra. Science 1971, 172 (3983), 567-570. 
31. Momma, K.; Izumi, F., VESTA 3 for three-dimensional visualization of crystal, volumetric and morphology data. J. Appl. Crystallogr. 2011, 44 (6), 1272-1276.

32. Knutson, J. L.; Martin, J. D.; Mitzi, D. B., Tuning the Band Gap in Hybrid Tin Iodide Perovskite Semiconductors Using Structural Templating. Inorg. Chem. 2005, 44 (13), 46994705.

33. Pedesseau, L.; Sapori, D.; Traore, B.; Robles, R.; Fang, H.-H.; Loi, M. A.; Tsai, H.; Nie, W.; Blancon, J.-C.; Neukirch, A.; Tretiak, S.; Mohite, A. D.; Katan, C.; Even, J.; Kepenekian, M., Advances and Promises of Layered Halide Hybrid Perovskite Semiconductors. ACS Nano 2016, 10 (11), 9776-9786.

34. Du, M. H., Efficient carrier transport in halide perovskites: theoretical perspectives. $J$. Mater. Chem. A 2014, 2 (24), 9091-9098.

35. Blancon, J. C.; Stier, A. V.; Tsai, H.; Nie, W.; Stoumpos, C. C.; Traoré, B.; Pedesseau, L.; Kepenekian, M.; Katsutani, F.; Noe, G. T.; Kono, J.; Tretiak, S.; Crooker, S. A.; Katan, C.; Kanatzidis, M. G.; Crochet, J. J.; Even, J.; Mohite, A. D., Scaling law for excitons in 2D perovskite quantum wells. Nat. Commun. 2018, 9 (1), 2254.

36. Hautzinger, M. P.; Pan, D.; Pigg, A. K.; Fu, Y.; Morrow, D.; Leng, M.; Kuo, M.-Y.; Spitha, N.; Lafayette, D. P.; Kohler, D. D.; Wright, J. C.; Jin, S., Band Edge Tuning of 2D Ruddlesden-Popper Perovskites by A Cation Size Revealed through Nanoplates. ACS Energy Lett. 2020, 5, 1430-1437.

37. Wang, N.; Liu, W.; Zhang, Q., Perovskite-Based Nanocrystals: Synthesis and Applications beyond Solar Cells. Small Meth. 2018, 2 (6), 1700380.

38. Li, X.; Do, T. T. H.; Granados del Águila, A.; Huang, Y.; Chen, W.; Xiong, Q.; Zhang, Q., A 3D Haloplumbate Framework Constructed From Unprecedented Lindqvist-like Highly Coordinated $\left[\mathrm{Pb}_{6} \mathrm{Br}_{25}\right]_{13}$ - Nanoclusters with Temperature-Dependent Emission. Chem. - Asian J. 2018, 13 (21), 3185-3189.

39. Li, X.; Ha Do, T. T.; Granados del Águila, A.; Huang, Y.; Chen, W.; Li, Y.; Ganguly, R.; Morris, S.; Xiong, Q.; Li, D.-s.; Zhang, Q., Two-Dimensional and Emission-Tunable: An Unusual Perovskite Constructed from Lindqvist-Type $\left[\mathrm{Pb}_{6} \mathrm{Br}_{19}\right]_{7}-$ Nanoclusters. Inorg. Chem. 2018, 57 (22), 14035-14038.

40. De Angelis, F.; Petrozza, A., Clues from defect photochemistry. Nat. Mater. 2018, 17 (5), 383-384.

41. Stranks, S. D.; Burlakov, V. M.; Leijtens, T.; Ball, J. M.; Goriely, A.; Snaith, H. J., Recombination Kinetics in Organic-Inorganic Perovskites: Excitons, Free Charge, and Subgap States. Phys. Rev. Appl. 2014, 2 (3), 034007.

42. $\quad$ Liang, M.; Lin, W.; Lan, Z.; Meng, J.; Zhao, Q.; Zou, X.; Castelli, I. E.; Pullerits, T.; Canton, S. E.; Zheng, K., Electronic Structure and Trap States of Two-Dimensional RuddlesdenPopper Perovskites with the Relaxed Goldschmidt Tolerance Factor. ACS Applied Electronic Materials 2020, 2 (5), 1402-1412.

43. Delport, G.; Chehade, G.; Lédée, F.; Diab, H.; Milesi-Brault, C.; Trippé-Allard, G.; Even, J.; Lauret, J.-S.; Deleporte, E.; Garrot, D., Exciton-Exciton Annihilation in Two-Dimensional Halide Perovskites at Room Temperature. J. Phys. Chem. Lett. 2019, 10 (17), 5153-5159.

44. Deng, S.; Shi, E.; Yuan, L.; Jin, L.; Dou, L.; Huang, L., Long-range exciton transport and slow annihilation in two-dimensional hybrid perovskites. Nat. Commun. 2020, 11 (1), 664.

45. Fabini, D. H.; Laurita, G.; Bechtel, J. S.; Stoumpos, C. C.; Evans, H. A.; Kontos, A. G.; Raptis, Y. S.; Falaras, P.; Van der Ven, A.; Kanatzidis, M. G.; Seshadri, R., Dynamic 
Stereochemical Activity of the $\mathrm{Sn}^{2+}$ Lone Pair in Perovskite CsSnBr 3 . J. Am. Chem. Soc. 2016, 138 (36), 11820-11832.

46. Yaffe, O.; Guo, Y.; Tan, L. Z.; Egger, D. A.; Hull, T.; Stoumpos, C. C.; Zheng, F.; Heinz, T. F.; Kronik, L.; Kanatzidis, M. G.; Owen, J. S.; Rappe, A. M.; Pimenta, M. A.; Brus, L. E., Local Polar Fluctuations in Lead Halide Perovskite Crystals. Phys. Rev. Lett. 2017, 118 (13), 136001.

47. Quarti, C.; Grancini, G.; Mosconi, E.; Bruno, P.; Ball, J. M.; Lee, M. M.; Snaith, H. J.; Petrozza, A.; De Angelis, F., The Raman Spectrum of the $\mathrm{CH}_{3} \mathrm{NH}_{3} \mathrm{PbI}_{3}$ Hybrid Perovskite: Interplay of Theory and Experiment. J. Phys. Chem. Lett. 2014, 5 (2), 279-284.

48. Zhu, H.; Miyata, K.; Fu, Y.; Wang, J.; Joshi, P. P.; Niesner, D.; Williams, K. W.; Jin, S.; Zhu, X.-Y., Screening in crystalline liquids protects energetic carriers in hybrid perovskites.

Science 2016, 353 (6306), 1409-1413.

49. Miyata, K.; Atallah, T. L.; Zhu, X.-Y., Lead halide perovskites: Crystal-liquid duality, phonon glass electron crystals, and large polaron formation. Sci. Adv. 2017, 3 (10), 1701469.

50. Pérez-Osorio, M. A.; Lin, Q.; Phillips, R. T.; Milot, R. L.; Herz, L. M.; Johnston, M. B.; Giustino, F., Raman Spectrum of the Organic-Inorganic Halide Perovskite $\mathrm{CH}_{3} \mathrm{NH}_{3} \mathrm{PbI}_{3}$ from First Principles and High-Resolution Low-Temperature Raman Measurements. J. Phys. Chem. C 2018, 122 (38), 21703-21717.

51. Guo, P.; Xia, Y.; Gong, J.; Cao, D. H.; Li, X.; Li, X.; Zhang, Q.; Stoumpos, C. C.; Kirschner, M. S.; Wen, H.; Prakapenka, V. B.; Ketterson, J. B.; Martinson, A. B. F.; Xu, T.; Kanatzidis, M. G.; Chan, M. K. Y.; Schaller, R. D., Direct Observation of Bandgap Oscillations Induced by Optical Phonons in Hybrid Lead Iodide Perovskites. Adv. Funct. Mater. 2020, 1907982.

52. Yang, Y.; Ostrowski, D. P.; France, R. M.; Zhu, K.; van de Lagemaat, J.; Luther, J. M.; Beard, M. C., Observation of a hot-phonon bottleneck in lead-iodide perovskites. Nat. Photonics 2015, 10, 53.

53. Liang, Y.; Shang, Q.; Wei, Q.; Zhao, L.; Liu, Z.; Shi, J.; Zhong, Y.; Chen, J.; Gao, Y.; Li, M.; Liu, X.; Xing, G.; Zhang, Q., Lasing from Mechanically Exfoliated 2D Homologous Ruddlesden-Popper Perovskite Engineered by Inorganic Layer Thickness. Adv. Mater. 2019, 31 (39), 1903030.

54. Wu, X.; Trinh, M. T.; Niesner, D.; Zhu, H.; Norman, Z.; Owen, J. S.; Yaffe, O.; Kudisch, B. J.; Zhu, X. Y., Trap States in Lead Iodide Perovskites. J. Am. Chem. Soc. 2015, 137 (5), 20892096.

55. Booker, E. P.; Thomas, T. H.; Quarti, C.; Stanton, M. R.; Dashwood, C. D.; Gillett, A. J.; Richter, J. M.; Pearson, A. J.; Davis, N. J. L. K.; Sirringhaus, H.; Price, M. B.; Greenham, N. C.; Beljonne, D.; Dutton, S. E.; Deschler, F., Formation of Long-Lived Color Centers for Broadband Visible Light Emission in Low-Dimensional Layered Perovskites. J. Am. Chem. Soc. 2017, 139 (51), 18632-18639.

56. Frost, J. M.; Walsh, A., What Is Moving in Hybrid Halide Perovskite Solar Cells? Acc. Chem. Res. 2016, 49 (3), 528-535.

57. Zhu, H.; Trinh, M. T.; Wang, J.; Fu, Y.; Joshi, P. P.; Miyata, K.; Jin, S.; Zhu, X. Y., Organic Cations Might Not Be Essential to the Remarkable Properties of Band Edge Carriers in Lead Halide Perovskites. Adv. Mater. 2017, 29 (1), 1603072.

58. Zheng, F.; Tan, L. Z.; Liu, S.; Rappe, A. M., Rashba Spin-Orbit Coupling Enhanced Carrier Lifetime in $\mathrm{CH}_{3} \mathrm{NH}_{3} \mathrm{PbI}_{3}$. Nano Lett. 2015, 15 (12), 7794-7800. 
Table 1. Crystal and Refinement Data for $(\mathrm{BA})_{2}(\mathrm{~A}) \mathrm{Pb}_{2} \mathrm{I}_{7}(\mathrm{~A}=\mathrm{MA}, \mathrm{FA}, \mathrm{DMA}$ and GA)

\begin{tabular}{|c|c|c|c|c|}
\hline $\begin{array}{l}\text { Compound } \\
\text { Crystal system }\end{array}$ & $\begin{array}{l}(\mathbf{B A})_{2}(\mathbf{M A}) \mathbf{P b}_{2} \mathbf{I}_{7} \\
\text { orthorhombic }\end{array}$ & $\begin{array}{l}(\mathbf{B A})_{2}(\mathbf{F A}) \mathbf{P b}_{2} \mathbf{I}_{7} \\
\text { orthorhombic }\end{array}$ & $\begin{array}{l}(\mathbf{B A})_{2}(\mathbf{D M A}) \mathbf{P b}_{2} \mathbf{I}_{7} \\
\text { orthorhombic }\end{array}$ & $\begin{array}{l}(\mathbf{B A})_{2}(\mathbf{G A}) \mathbf{P b}_{2} \mathbf{I}_{7} \\
\text { orthorhombic }\end{array}$ \\
\hline Space group & $\mathrm{Cmcm}$ & $\mathrm{Cmcm}$ & $C c m b$ & $\mathrm{Cmcm}$ \\
\hline $\begin{array}{l}\text { Unit cell } \\
\text { dimensions }\end{array}$ & $\begin{array}{l}\mathrm{a}=39.347(2) \AA \\
\mathrm{b}=8.9470(4) \AA \\
\mathrm{c}=8.8589(6) \AA\end{array}$ & $\begin{array}{l}\mathrm{a}=39.395(5) \\
\mathrm{b}=9.0237(10) \AA \\
\mathrm{c}=8.9612(9) \AA\end{array}$ & $\begin{array}{l}\mathrm{a}=39.730(4) \AA \\
\mathrm{b}=8.8756(6) \AA \\
\mathrm{c}=9.0616(9) \AA\end{array}$ & $\begin{array}{l}\mathrm{a}=39.262(5) \AA \\
\mathrm{b}=9.0894(10) \AA \\
\mathrm{c}=8.9518(9) \AA\end{array}$ \\
\hline Volume & $3118.7(3) \AA^{3}$ & $3185.6(6) \AA^{3}$ & $3195.4(5) \AA^{3}$ & $3194.6(6) \AA^{3}$ \\
\hline $\mathrm{Z}$ & 4 & 4 & 4 & 4 \\
\hline $\begin{array}{l}\text { Density } \\
\text { (calculated) }\end{array}$ & $3.159 \mathrm{~g} / \mathrm{cm}^{3}$ & $3.1194 \mathrm{~g} / \mathrm{cm}^{3}$ & $3.112 \mathrm{~g} / \mathrm{cm}^{3}$ & $3.1418 \mathrm{~g} / \mathrm{cm}^{3}$ \\
\hline Index ranges & $\begin{array}{l}-46<=\mathrm{h}<=46 \\
-10<=\mathrm{k}<=1 \\
-10<=1<=10\end{array}$ & $\begin{array}{l}-53<=\mathrm{h}<=53 \\
-12<=\mathrm{k}<=12 \\
-12<=\mathrm{l}<=11\end{array}$ & $\begin{array}{l}-54<=\mathrm{h}<=54 \\
-12<=\mathrm{k}<=12 \\
-12<=\mathrm{l}<=10\end{array}$ & $\begin{array}{l}-55<=\mathrm{h}<=55 \\
-12<=\mathrm{k}<=12 \\
-12<=\mathrm{l}<=12\end{array}$ \\
\hline $\begin{array}{l}\text { Independent } \\
\text { reflections }\end{array}$ & $\begin{array}{l}1378 \\
{\left[\mathrm{R}_{\mathrm{int}}=0.0365\right]}\end{array}$ & $\begin{array}{l}1566 \\
{\left[R_{\text {int }}=0.0623\right]}\end{array}$ & $\begin{array}{l}1535 \\
{\left[\mathrm{R}_{\text {int }}=0.0611\right]}\end{array}$ & $\begin{array}{l}1578 \\
{\left[\mathrm{R}_{\text {int }}=0.0549\right]}\end{array}$ \\
\hline $\begin{array}{l}\text { Completeness } \\
\text { to } \theta=25^{\circ}\end{array}$ & $99 \%$ & $99 \%$ & $98 \%$ & $100 \%$ \\
\hline $\begin{array}{l}\text { Data / } \\
\text { restraints / } \\
\text { parameters }\end{array}$ & 1378 / 2 / 42 & $1566 / 9 / 42$ & $1535 / 10 / 43$ & $1578 / 13 / 43$ \\
\hline $\begin{array}{l}\text { Goodness-of- } \\
\text { fit }\end{array}$ & 1.283 & 4.22 & 1.82 & 9.07 \\
\hline $\begin{array}{l}\text { Final } R \text { indices } \\
{[I>2 \sigma(I)]} \\
R \text { indices [all } \\
\text { data] }\end{array}$ & $\begin{array}{l}\mathrm{R}_{\mathrm{obs}}=0.0663 \\
\mathrm{w}_{\mathrm{obs}}=0.1592 \\
\mathrm{R}_{\mathrm{all}}=0.0706 \\
\mathrm{wR}_{\mathrm{all}}=0.1619\end{array}$ & $\begin{array}{l}\mathrm{R}_{\text {obs }}=0.0658 \\
\mathrm{wR}_{\mathrm{obs}}=0.0806 \\
\mathrm{R}_{\mathrm{all}}=0.0813 \\
\mathrm{w}_{\mathrm{all}}=0.0814\end{array}$ & $\begin{array}{l}\mathrm{R}_{\mathrm{obs}}=0.0405 \\
\mathrm{wR}_{\text {obs }}=0.0434 \\
\mathrm{R}_{\text {all }}=0.0633 \\
\mathrm{wR}_{\text {all }}=0.0452\end{array}$ & $\begin{array}{l}\mathrm{R}_{\mathrm{obs}}=0.0654 \\
\mathrm{wR}_{\mathrm{obs}}=0.1126 \\
\mathrm{R}_{\mathrm{all}}=0.0746 \\
\mathrm{w}_{\mathrm{all}}=0.1477\end{array}$ \\
\hline $\begin{array}{l}\text { Largest diff. } \\
\text { peak and hole }\end{array}$ & $\begin{array}{l}1.30 \text { and } \\
-2.31 \mathrm{e} \cdot \AA^{-3}\end{array}$ & $\begin{array}{l}1.90 \text { and } \\
-2.61 \mathrm{e} \cdot \AA^{-3}\end{array}$ & $\begin{array}{l}1.51 \text { and } \\
-1.02 \mathrm{e} \cdot \AA^{-3}\end{array}$ & $\begin{array}{l}3.92 \text { and } \\
-2.11 \mathrm{e} \cdot \AA^{-3}\end{array}$ \\
\hline
\end{tabular}


Table 2. Effective Radii of A-site cations $\left(\mathrm{R}_{\mathrm{A}, \mathrm{eff}}\right)$, Cage Volumes $\left(\mathrm{V}_{\text {cage }}\right)$, Average $\mathrm{Pb}-\mathrm{I}$ bond lengths $\left(\mathrm{d}_{\text {avg }}\right)$, Distortion Index (D), Bond-angle Variance $\left(\sigma^{2}\right)$, Interlayer $d$-spacing, Bandgap and PL Peak of the Compounds Reported Here.

\begin{tabular}{|c|c|c|c|c|}
\hline Compound & $(\mathrm{BA})_{2}(\mathrm{MA}) \mathrm{Pb}_{2} \mathbf{I}_{7}$ & $(\mathrm{BA})_{2}(\mathrm{FA}) \mathrm{Pb}_{2} \mathbf{I}_{7}$ & $(\mathbf{B A})_{2}(\mathrm{DMA}) \mathrm{Pb}_{2} \mathbf{I}_{7}$ & $(\mathbf{B A})_{2}(\mathrm{GA}) \mathrm{Pb}_{2} \mathbf{I}_{7}$ \\
\hline $\mathbf{R}_{\mathrm{A}, \mathrm{eff}}$ & 217 & 253 & 272 & 278 \\
\hline$V_{\text {cage }}\left(\AA^{3}\right)$ & 248.6 & 256.0 & 256.9 & 258.7 \\
\hline $\mathbf{d}_{\text {avg }}(\AA \AA)$ & 3.17 & 3.19 & 3.20 & 3.21 \\
\hline D $\left(10^{-3}\right)$ & 10.4 & 14.8 & 18.4 & 19.1 \\
\hline$\sigma^{2}$ & 2.7 & 5.2 & 17.5 & 5.0 \\
\hline $\begin{array}{c}\text { Interlayer } \\
\text { d-spacing }(\AA)\end{array}$ & 7.13 & 7.03 & 7.09 & 6.91 \\
\hline Bandgap (eV) & 2.16 & 2.18 & 2.22 & 2.20 \\
\hline PL peak (eV) & 2.12 & 2.14 & 2.18 & 2.17 \\
\hline
\end{tabular}

Table 3. Equatorial $\mathrm{Pb}-\mathrm{I}$ Bond Lengths, Axial $\mathrm{Pb}-\mathrm{I}$ Bond Lengths (internal and external), Average Equatorial $\mathrm{Pb}-\mathrm{I}$ Bond Length and Average Axial $\mathrm{Pb}-\mathrm{I}$ Bond Length of the Compounds Reported Here.

\begin{tabular}{|c|c|c|c|c|}
\hline Compound & $(\mathrm{BA})_{2}(\mathrm{MA}) \mathrm{Pb}_{2} \mathrm{I}_{7}$ & $(\mathrm{BA})_{2}(\mathrm{FA}) \mathrm{Pb}_{2} \mathrm{I}_{7}$ & $(\mathrm{BA})_{2}(\mathrm{DMA}) \mathrm{Pb}_{2} \mathrm{I}_{7}$ & $(\mathrm{BA})_{2}(\mathrm{GA}) \mathrm{Pb}_{2} \mathrm{I}_{7}$ \\
\hline \multirow{2}{*}{ Equatorial } & $3.1644(7)$ & $3.1926(9)$ & $3.2043(6)$ & $3.2007(8)$ \\
\hline & $3.1644(7)$ & $3.1926(9)$ & $3.2043(6)$ & $3.2007(8)$ \\
\hline \multirow[t]{2}{*}{$\mathbf{P b}-\mathbf{I}(\AA)$} & $3.1721(8)$ & $3.1963(9)$ & $3.1816(6)$ & $3.2131(8)$ \\
\hline & $3.1721(8)$ & $3.1963(9)$ & $3.1816(6)$ & $3.2131(8)$ \\
\hline 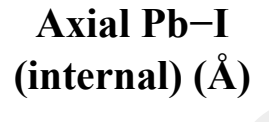 & $3.2633(10)$ & $3.3312(13)$ & $3.3699(10)$ & $3.3788(14)$ \\
\hline $\begin{array}{c}\text { Axial Pb-I } \\
\text { (external) (A) }\end{array}$ & $3.081(2)$ & $3.055(3)$ & $3.0623(18)$ & $3.037(3)$ \\
\hline $\begin{array}{c}\text { Ave eq Pb-I } \\
(\AA)\end{array}$ & $3.1683(7)$ & $3.1945(9)$ & $3.1930(6)$ & $3.2069(8)$ \\
\hline $\begin{array}{c}\text { Ave ax Pb-I } \\
(\AA)\end{array}$ & $3.1722(15)$ & $3.1931(22)$ & $3.2161(14)$ & $3.2079(22)$ \\
\hline
\end{tabular}


Table 4. Equatorial, Axial and Average $\mathrm{Pb}-\mathrm{I}-\mathrm{Pb}$ angles of the Compounds Reported Here

\begin{tabular}{|c|c|c|c|c|}
\hline Compound & $(\mathrm{BA})_{2}(\mathrm{MA}) \mathrm{Pb}_{2} \mathrm{I}_{7}$ & $(\mathbf{B A})_{2}(\mathbf{F A}) \mathrm{Pb}_{2} \mathbf{I}_{7}$ & $(\mathrm{BA})_{2}(\mathrm{DMA}) \mathrm{Pb}_{2} \mathrm{I}_{7}$ & $(\mathrm{BA})_{2}(\mathbf{G A}) \mathrm{Pb}_{2} \mathbf{I}_{7}$ \\
\hline Equatorial & 164.5 & 172.9 & 165.2 & 169.1 \\
\hline $\mathbf{P b}-\mathbf{I}-\mathbf{P b}\left(^{\circ}\right)$ & 169.9 & 165.9 & 168.1 & 167.0 \\
\hline Axial Pb-I-Pb ( $\left.{ }^{\circ}\right)$ & 165.6 & 171.3 & 180.0 & 171.8 \\
\hline $\begin{array}{c}\text { Ave equatorial } \\
\mathbf{P b}-\mathbf{I}-\mathbf{P b}\left(^{\circ}\right)\end{array}$ & 167.2 & 169.4 & 166.6 & 168.1 \\
\hline Ave $\mathrm{Pb}-\mathrm{I}-\mathrm{Pb}\left(^{\circ}\right)$ & 166.7 & 170.0 & 171.1 & 169.3 \\
\hline
\end{tabular}


a

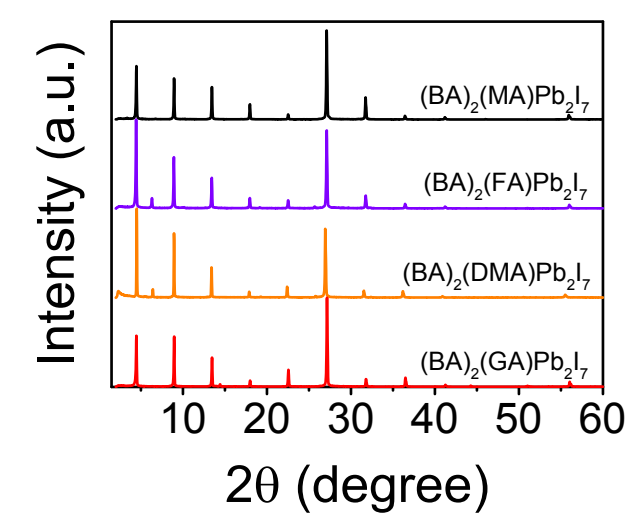

b c c

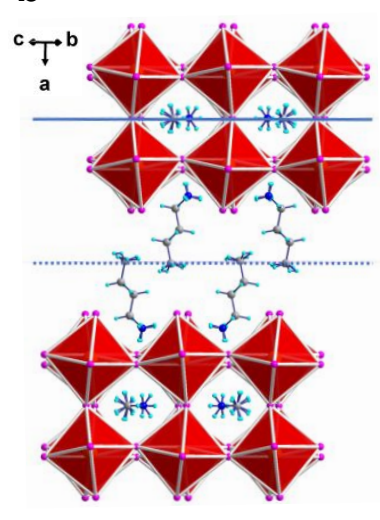

f

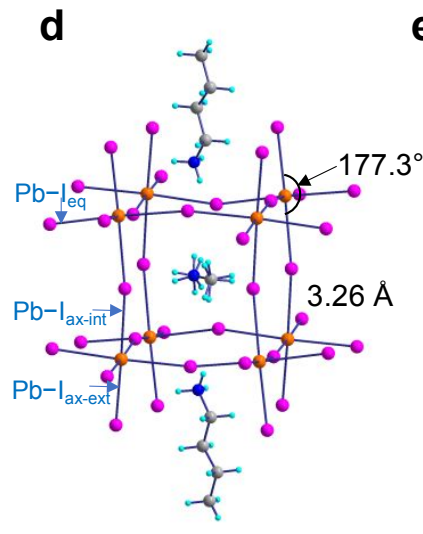

e
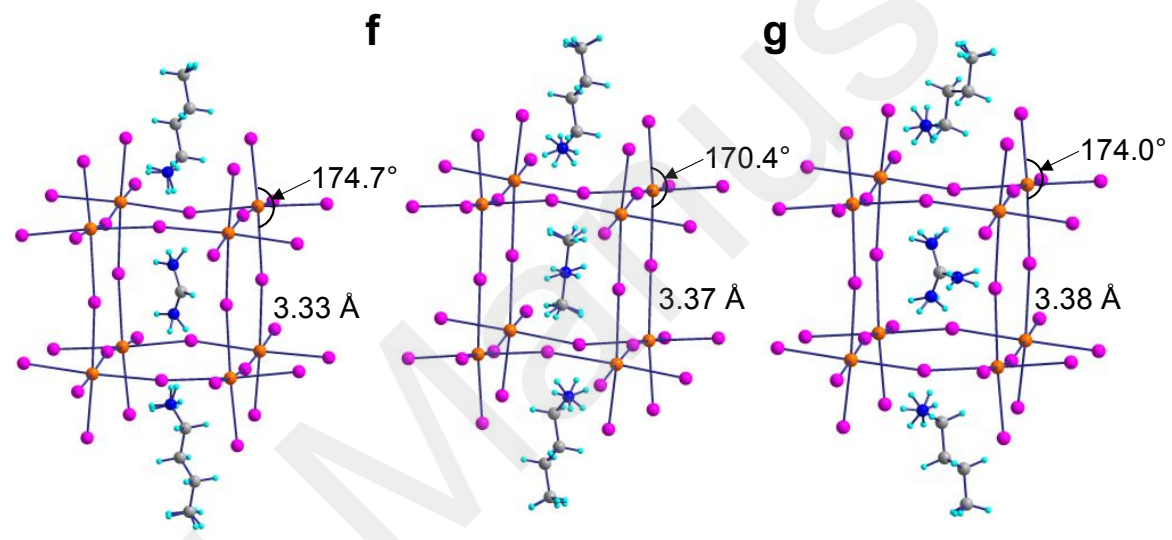

Figure 1. (a) PXRD patterns of the compounds reported here. (b) Crystal structure of $(\mathrm{BA})_{2}(\mathrm{MA}) \mathrm{Pb}_{2} \mathrm{I}_{7}$ and (c) $(\mathrm{BA})_{2}(\mathrm{DMA}) \mathrm{Pb}_{2} \mathrm{I}_{7}$ from side view. The dash line represents the glide plane and the solid line indicates the mirror plane. Crystal structures of (d) $(\mathrm{BA})_{2}(\mathrm{MA}) \mathrm{Pb}_{2} \mathrm{I}_{7}$, (e) $(\mathrm{BA})_{2}(\mathrm{FA}) \mathrm{Pb}_{2} \mathrm{I}_{7}$, (f) $(\mathrm{BA})_{2}(\mathrm{DMA}) \mathrm{Pb}_{2} \mathrm{I}_{7}$ and $(\mathrm{g})(\mathrm{BA})_{2}(\mathrm{GA}) \mathrm{Pb}_{2} \mathrm{I}_{7}$ emphasizing the cage defined by eight adjacent $\mathrm{Pb}$ atoms. 


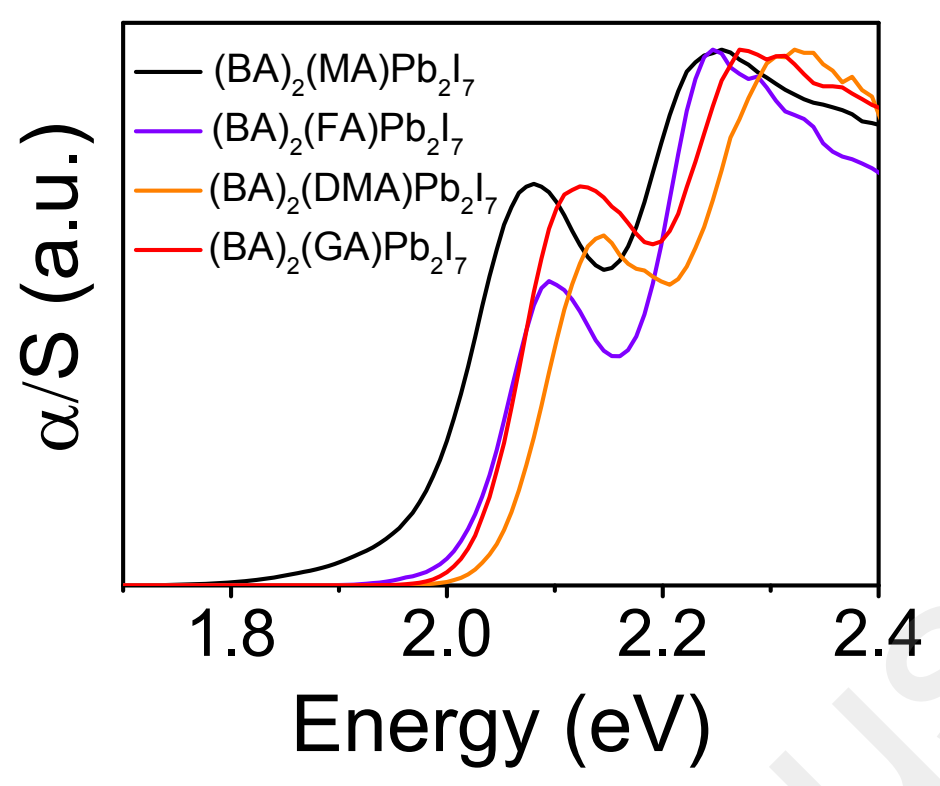

Figure 2. Optical absorption spectra of the 2D perovskite compounds reported here. 

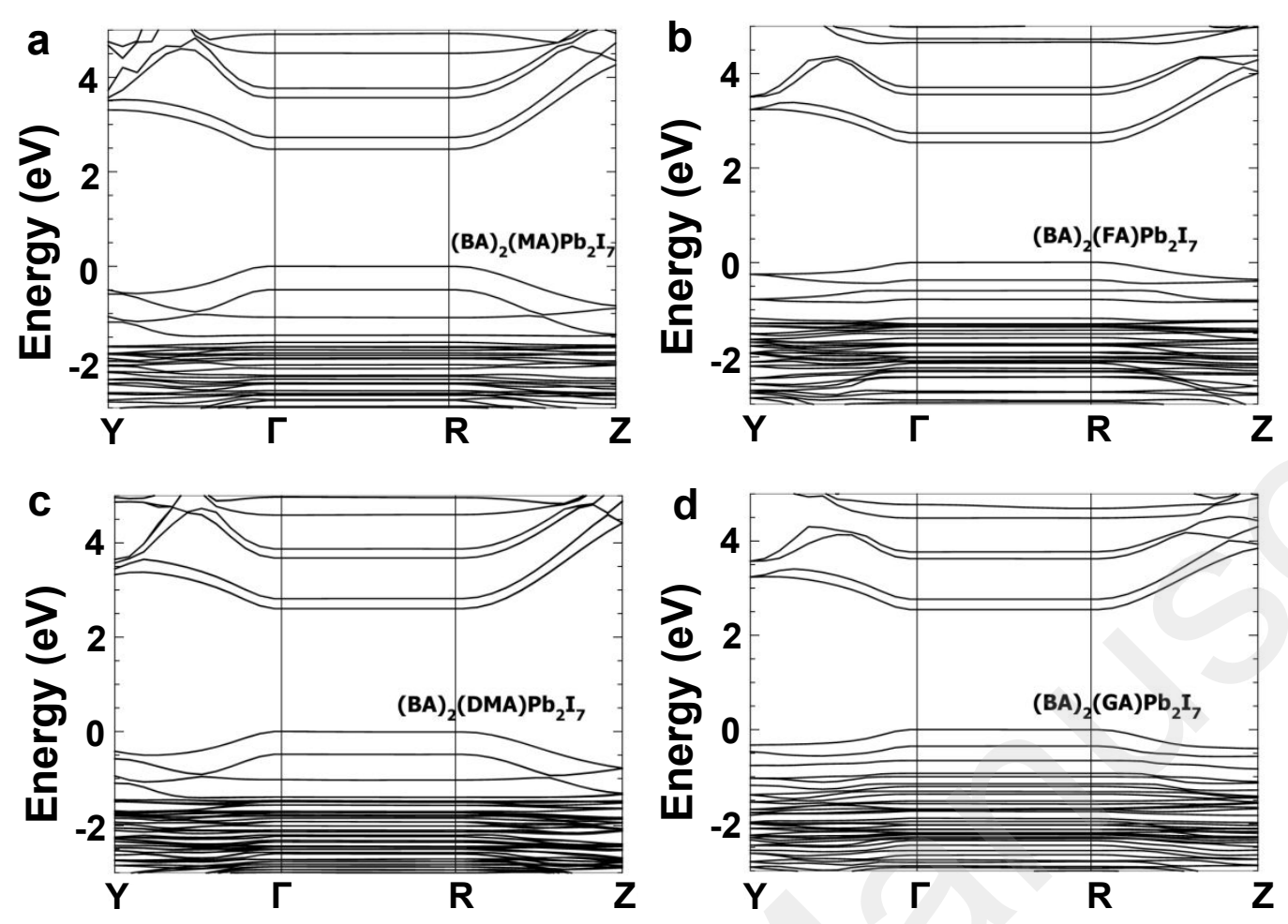

Figure 3. Computed electronic band structures for (a) (BA) $)_{2}(\mathrm{MA}) \mathrm{Pb}_{2} \mathrm{I}_{7}$, (b) (BA) $)_{2}(\mathrm{FA}) \mathrm{Pb}_{2} \mathrm{I}_{7}$, (c) $(\mathrm{BA})_{2}(\mathrm{DMA}) \mathrm{Pb}_{2} \mathrm{I}_{7}$ and $(\mathrm{d})(\mathrm{BA})_{2}(\mathrm{GA}) \mathrm{Pb}_{2} \mathrm{I}_{7}$. The DFT calculations have been performed at the HSE+SOC level of theory with $73 \%$ of Fock exchange. 

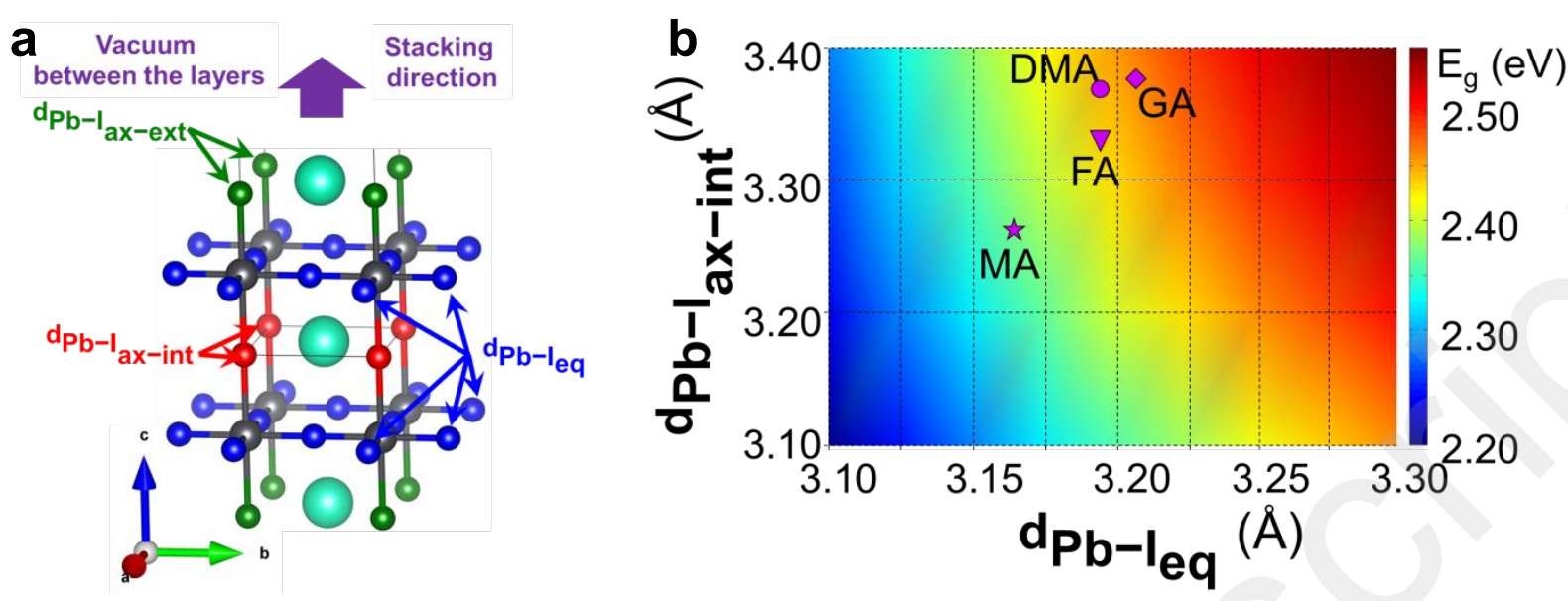

Figure 4. (a) Schematic representation of the all inorganic $2 \mathrm{D}$ model compound $\left(\mathrm{Cs}_{3} \mathrm{~Pb}_{2} \mathrm{I}_{7}\right)$

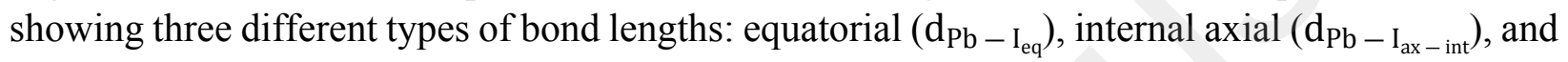
external axial $\left(\mathrm{d}_{\mathrm{Pb}-\mathrm{I}_{\mathrm{ax}-\mathrm{ext}}}\right)$ lead-iodide bond lengths. (b) 2D color map of computed electronic bandgap energies $\left(E_{g}\right)$ for different values of equatorial $\left(d_{P b}-I_{e q}\right)$ and internal axial $\left(d_{P b}-I_{a x-i n t}\right)$ distances, setting $\mathrm{d}_{\mathrm{Pb}-\mathrm{I}_{\mathrm{ax}-\mathrm{ext}}}$ to $3.1 \AA$, overlaid by the experimental bond lengths extracted from single crystal structures for $(\mathrm{BA})_{2}(\mathrm{MA}) \mathrm{Pb}_{2} \mathrm{I}_{7}(\mathrm{MA}),(\mathrm{BA})_{2}(\mathrm{FA}) \mathrm{Pb}_{2} \mathrm{I}_{7}(\mathrm{FA}),(\mathrm{BA})_{2}(\mathrm{DMA}) \mathrm{Pb}_{2} \mathrm{I}_{7}$ (DMA) and (BA) $)_{2}(\mathrm{GA}) \mathrm{Pb}_{2} \mathrm{I}_{7}(\mathrm{GA})$. 

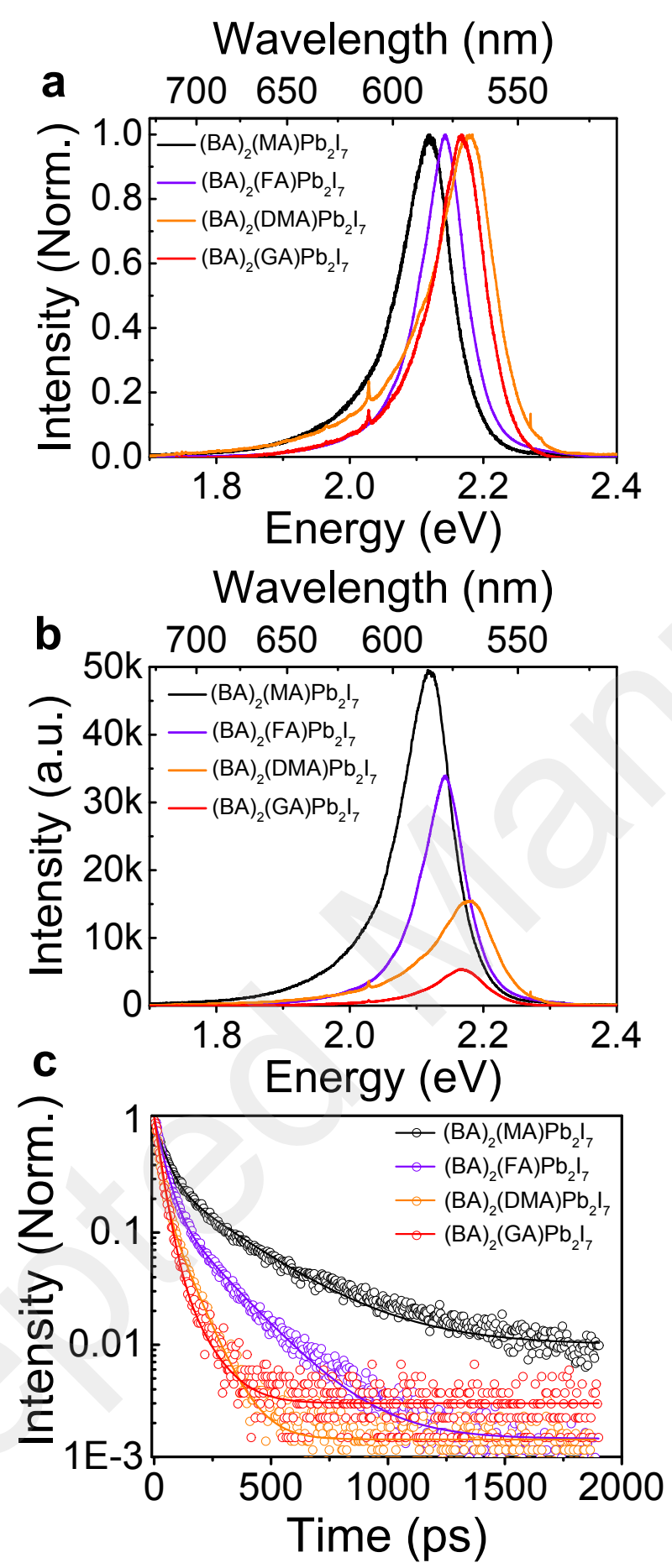

Figure 5. (a) normalized PL spectra, (b) unnormalized PL spectra and (c) normalized timeresolved PL decay of the $2 \mathrm{D}$ perovskite compounds reported here. 


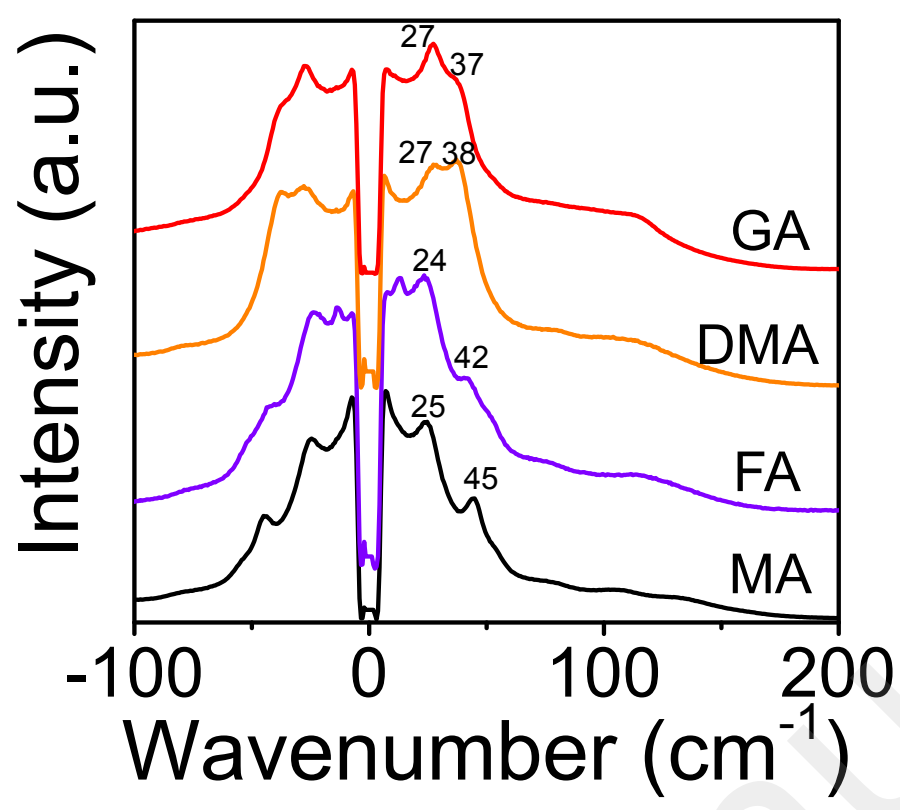

Figure 6. Raman spectra of 2D compounds reported here, the numbers indicate the peak positions in $\mathrm{cm}^{-1}$. 

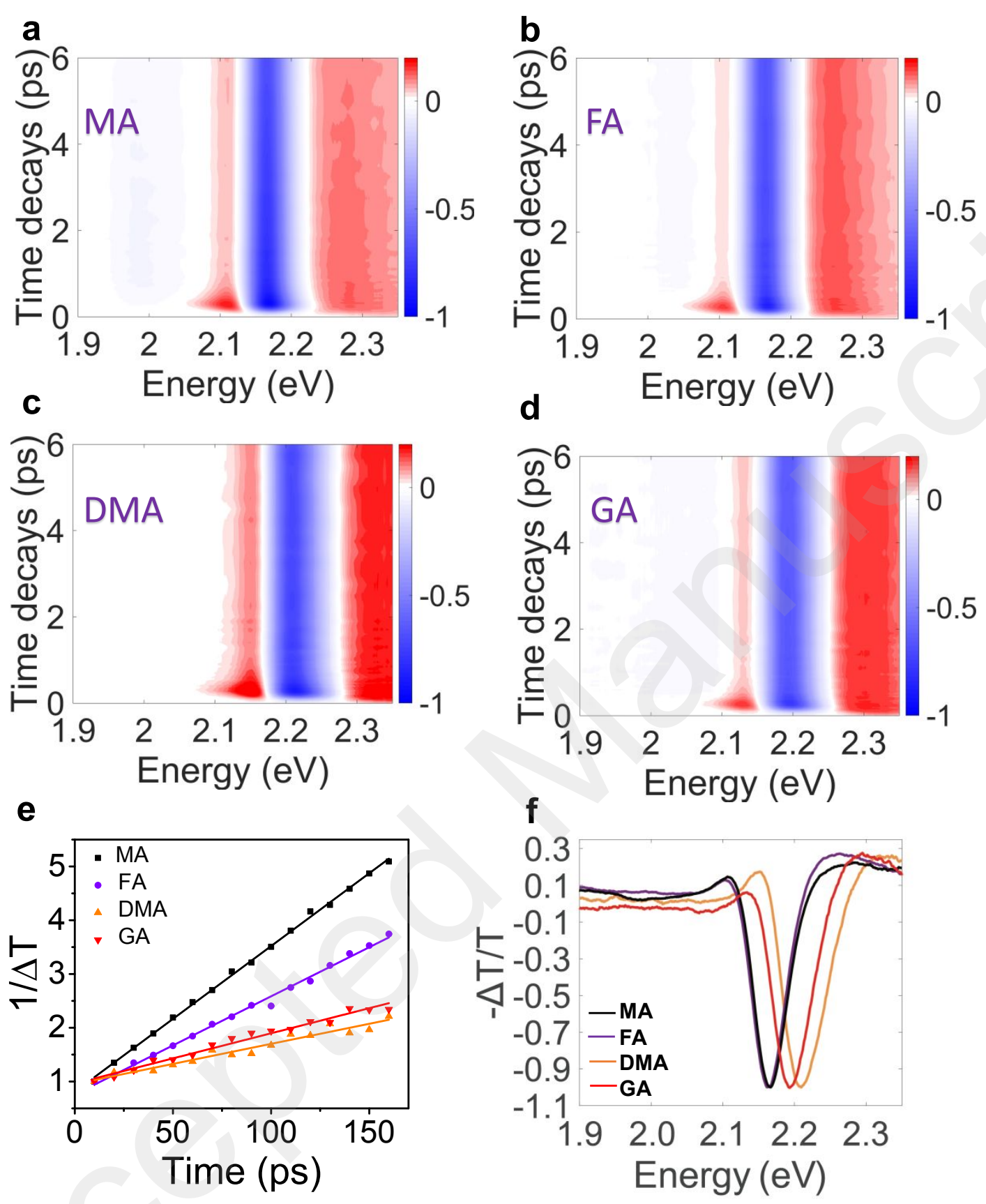

Figure 7. Two-dimensional pseudocolor $(-\Delta \mathrm{T} / \mathrm{T})$ plots of TA spectra for (a) $(\mathrm{BA})_{2}(\mathrm{MA}) \mathrm{Pb}_{2} \mathrm{I}_{7}$, (b) $(\mathrm{BA})_{2}(\mathrm{FA}) \mathrm{Pb}_{2} \mathrm{I}_{7}$, (c) $(\mathrm{BA})_{2}(\mathrm{DMA}) \mathrm{Pb}_{2} \mathrm{I}_{7}$ and (d) $(\mathrm{BA})_{2}(\mathrm{GA}) \mathrm{Pb}_{2} \mathrm{I}_{7}$ at the first 6 ps. The blue areas represent bleaching and the red ones are photo-induced absorption. (e) Experimental (symbols) and fitted (lines) $1 / \Delta T \sim t$ plots of the ground-state bleaching peaks for compounds reported here. (f) TA spectra cuts at 10 ps for compounds reported here. 
TOC
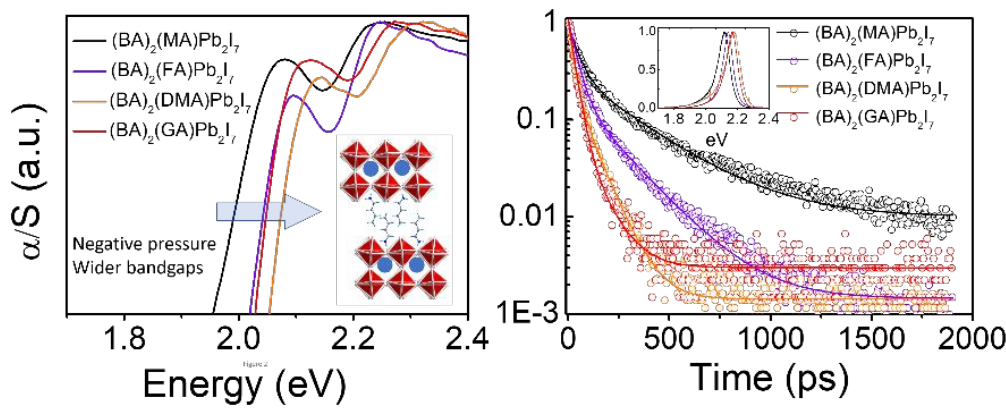

7 